\title{
Influence of Fe-Doping on the Structural and Magnetic Properties of ZnO Nanopowders, Produced by the Method of Pulsed Electron Beam Evaporation
}

\author{
V. G. Il'ves, ${ }^{1,2}$ S. Yu. Sokovnin, ${ }^{1,2}$ and A. M. Murzakaev ${ }^{1,2}$ \\ ${ }^{1}$ Institute of Electrophysics, Russian Academy of Sciences, Ural Branch, Amundsen Street 106, Yekaterinburg 620016, Russia \\ ${ }^{2}$ Yeltsin Ural Federal University, Mira Street 19, Yekaterinburg 620002, Russia \\ Correspondence should be addressed to V. G. Il'ves; ilves@iep.uran.ru
}

Received 24 July 2015; Accepted 10 February 2016

Academic Editor: Oded Millo

Copyright ( 2016 V. G. Il'ves et al. This is an open access article distributed under the Creative Commons Attribution License, which permits unrestricted use, distribution, and reproduction in any medium, provided the original work is properly cited.

\begin{abstract}
The nanopowders (NPs) $\mathrm{ZnO}-\mathrm{Zn}-\mathrm{Fe}$ and $\mathrm{ZnO}$-Fe with the various concentrations of $\mathrm{Fe}\left(x_{\mathrm{Fe}}\right)\left(0 \leq x_{\mathrm{Fe}} \leq 0.619\right.$ mass.\%) were prepared by the pulsed electron beam evaporation method. The influence of doping Fe on structural and magnetic properties of NPs was investigated. X-ray diffraction showed that powders contain fine-crystalline and coarse-crystalline ZnO fractions with wurtzite structure and an amorphous component. Secondary phases were not found. The magnetic measurements made at room temperature, using the vibration magnetometer and Faraday's scales, showed ferromagnetic behavior for all powders. Magnetization growth of NPs $\mathrm{ZnO}-\mathrm{Zn}$ and $\mathrm{ZnO}-\mathrm{Zn}-\mathrm{Fe}$ was detected after their short-term annealing on air at temperatures of $300-500^{\circ} \mathrm{C}$. The growth of magnetization is connected with the increase in the concentration of the phase $\mathrm{ZnO}$ with a defective structure as the result of oxidation nanoparticles (NPles) of Zn. The scanning transmission electron microscopy (STEM) showed a lack of Fe clusters and uniform distribution of atoms dopant in the initial powder $\mathrm{ZnO}-\mathrm{Zn}-\mathrm{Fe}$. A lack of logical correlation between magnetization and concentration of a magnetic dopant of Fe in powders is shown.
\end{abstract}

\section{Introduction}

The diluted magnetic semiconductors (DMS) cause a great interest due to their potential use in spintronics devices [14]. Materials of spintronics have to be steady against the influences of normal environment (to pressure, temperature, and humidity), in order to be integrated with elements of modern silicon electronics; the time of spin coherence should not be too short (>100 ns), to possess high mobility of charge carriers and to be ferromagnetic at room temperature [5]. The active search of ferromagnetic nanostructured DMS is considered to be the most attractive since the semiconductor nanostructuring allows for increase of solubility of transitional metal impurity in its crystal lattice to desirable level of $1-2 \%$ for providing the magneto ordered condition and suppresses the undesirable aggregation of impurity in clusters. It is expected that the nanostructured materials at temperature of Curie will be significantly higher than in volume materials [5-8].

Now there is no theory explaining the nature of ferromagnetism in the various DMS $[9,10]$ types and ambiguity of experimental data. In many works there is an indication of a lack of logical correlation between magnetization of DSM and concentration of a magnetic dopant [11-13]. Often, the ferromagnetic response of undoped materials (so-called $\mathrm{d}^{0}$ ferromagnetism) surpasses the corresponding response in doped materials by magnetic 3D elements semiconductors and oxides [14-19]. There are not yet enough studies in which the investigated materials with concentrations of magnetic dopants below a percolation threshold have been observed.

It should be noted that direct exchange interaction cannot result in ferromagnetism of DMS since the distance between the neighboring magnetic ions is rather great for their electron shells to be overlapped. Therefore research into the 
nature of ferromagnetic ordering in DMS at the expense of indirect exchange interaction via carriers of charge is actual $[5,20]$.

$\mathrm{Zn}_{1-x} \mathrm{Fe}_{x} \mathrm{O}$ ferromagnetic semiconductors with a temperature of Curie higher than the room were performed using the sol-gel method [21], solid-state reaction route [22, 23], magnetron sputtering [24], and a number of other methods.

For the synthesis of nanoparticles $\mathrm{ZnO}-\mathrm{Fe}$ a spherical crushing (ball milling) $[25,26]$ was used along with the sol-gel method [27-31], codeposition [32-35], pulsed laser deposition [36], burning of solutions [37], microwave synthesis [38], flame spray pyrolysis $[39,40]$, chemical pyrophoric reaction method [41], the method of autocombustion [42], and so forth.

The analysis of literature showed that irrespective of a method for obtaining nanoparticles and a type of the nanostructured material (thin films, nanopowders, nanostructures with various morphologies, nanorods, nanowires, nanodisks, nanotetrapods, etc.) in $\mathrm{ZnO}-\mathrm{Fe}$ system general regularities are observed: with the growth of Fe dopant concentration the size of nanoparticles, crystallinity, and width of the bandgap zone decrease [28, 32, 33, 40, 43, 44]; when annealing samples with concentration of Fe dopant from 2-5 mass.\% and above, with the growth of annealing temperature the formation of the secondary phase-spinel $\mathrm{ZnFe}_{2} \mathrm{O}_{4}$ dominates [23, 27, 42, $43,45,46]$. The formation of other secondary phases, $\mathrm{Fe}_{3} \mathrm{O}_{4}$ [47] and $\alpha$-Fe [48], was observed. More often the mixed valency of dopant ions $\left(\mathrm{Fe}^{2+}\right.$ and $\left.\mathrm{Fe}^{3+}\right)$ was reported in the final product $[23,28,46,48,49]$.

At the concentration of $\mathrm{Fe}$ in $\mathrm{ZnO}-\mathrm{Fe}$ system higher than 1 at.\%, magnetization of samples usually changes linearly (grows [35, 37, 44, 50] or decreases [24]) with increase of dopant concentration $[23,28,35,51]$ up to the moment of emergence secondary phases. However, at a lower level of doping (less than 1 at\% Fe), a nonlinear course of dependence magnetization was noted from Fe concentration [38].

The general tendency in change of magnetization in the $\mathrm{ZnO}-\mathrm{Fe}$ system with growth of dopant concentration is the strengthening of paramagnetic contribution to total magnetization (the curve of magnetization does not reach saturation even in big magnetic field $\pm 50 \mathrm{kOe}$ ). Note the considerable dispersion in absolute magnitudes of magnetization in the various nanomaterials $\mathrm{ZnO}-\mathrm{Fe}$ and big variations of solubility limit of Fe in ZnO lattice (from 1 [23] up to 21 [33] mass. Fe\%) which depend on the methods and conditions of synthesis samples $\mathrm{ZnO}-\mathrm{Fe}$ [10]. In particular, in [52] it was shown that $\mathrm{ZnO}$ sample with $1 \% \mathrm{Fe}$ shows diamagnetic behavior though samples from 2 and $3 \%$ Fe show the ferromagnetic nature, and samples with higher doping level of Fe show paramagnetism; in [22] NPs $\mathrm{Zn}_{1-x} \mathrm{Fe}_{x} \mathrm{O}(x=0.02,0.04,0.06,0.08,0.10)$, received by the sol-gel method, show the room temperature ferromagnetism (RTFM) at 2\% Fe; other NPs (concentration of Fe $x_{\mathrm{Fe}} \geq 4 \%$ ) show paramagnetic properties.

The strengthening ferromagnetism in Fe-doped $\mathrm{ZnO}$ when annealing samples in a reduced atmosphere of $\mathrm{Ar} / \mathrm{H} 2$ (5\%) was documented [21]. Research of aging nanoparticles of $\mathrm{ZnO}$ and $\mathrm{ZnO}-\mathrm{Fe}$ (the forced hydrolysis) showed considerable degradation of ferromagnetic properties. Unusual growth of nanoparticles $\mathrm{ZnO}$ and $\mathrm{ZnO}-\mathrm{Fe}$ prepared by method of forced hydrolysis and easing of their ferromagnetic properties within 1-4 years was observed thanks to aging in the environment (the size of particles in sample of $\mathrm{Zn}_{0.95} \mathrm{Fe}_{0.05} \mathrm{O}$ changed from $7.9 \mathrm{~nm}$ to $9.0 \mathrm{~nm}$, and magnetization decreased with $1 * 10^{-3}$ to $2 * 10^{-4} \mathrm{emu} / \mathrm{g}$ ) as shown in work [34]. The temporary instability of powders partly can be one of sources of divergence of experimental data in literature.

In samples of $\mathrm{ZnO}$, doped with various $3 \mathrm{D}$ elements, antiferromagnetism $[53,54]$, spin-glass behavior $[52,55]$, and paramagnetism were observed $[56,57]$. These supervisions indicate a strong dependence of RTFM on conditions of preparation samples DSM [10]. In separate messages there was a very low temperature of magnetic ordering specified in such systems [58].

Thus, the situation with existence and explanation of RTFM nature in $\mathrm{ZnO}-\mathrm{Fe}$ system is very ambiguous.

The purpose of these efforts is to investigate the influence of structural defects on the magnetic properties of nanopowders $\mathrm{ZnO}-\mathrm{Fe}$ received by pulsed electron beam evaporation $[59,60]$, at the small concentration of magnetic dopant $\mathrm{Fe}$ (less than 1 mass.\%).

\section{Experiments}

The $\mathrm{ZnO}-\mathrm{Zn}-\mathrm{Fe}$ and $\mathrm{ZnO}-\mathrm{Zn}$ NPs were deposited on glass substrates by pulsed electron beam evaporation at the "Nanobeam-2" installation [59, 60], in vacuum (the operation pressure was $4 \mathrm{~Pa}$ ). During the deposition, the temperature of substrates was approximately $100-200^{\circ} \mathrm{C}$. Ceramic targets with nominal composition $\mathrm{ZnO}$-(1-3-5 mass\%) $\mathrm{Fe}_{2} \mathrm{O}_{3}$ were fabricated by a standard solid state reaction method. Appropriate proportions required for $\mathrm{ZnO}-(1-3-5 \%) \mathrm{Fe}_{2} \mathrm{O}_{3}$ were mixed by manual grinding according to the desired stoichiometry and pelletized, sintered at $1000^{\circ} \mathrm{C}$ for 1 hour.

The mode of evaporation was as follows: an accelerating voltage of $40 \mathrm{kV}$, an electron beam current of $0,4 \mathrm{~A}$, pulse length of $100 \mu \mathrm{s}$, pulse repetition rate of $100 \mathrm{~Hz}$, scanning area of the electron beam on the target of $2,5 \mathrm{sm}^{2}$, and time of evaporation of $30 \mathrm{~min}$. All nanopowders had black color. After annealing in air NPs were changed to a white-grey color due to oxidation of $\mathrm{Zn}$ nanoparticles (NPles).

The percentages of $\mathrm{Fe}$ in the samples were checked by a iCAP 6300 ICP spectrometer and energy-dispersive X-ray spectroscopy (EDX). The crystal structure of the $\mathrm{Zn}_{1-x} \mathrm{Fe}_{x} \mathrm{O}$ $(x=0.0061)$ was characterized by Shimadzu X-ray diffractometer XRD-7000 with nickel-filtered $\mathrm{Cu} \mathrm{K} \alpha$ radiation. The specific surface area of powders $\left(S_{\mathrm{BET}}\right)$ was determined by the Brunauer-Emmett-Teller (BET) method on a Micromeritics TriStar 3000 setup.

Thermograms and the mass spectra of the samples were recorded with differential scanning calorimetry (DSC) and thermogravimetry (TG) using an STA_409_PC Luxx synchronous thermoanalyzer, coupled with a QMS_403C mass spectrometer (resolution $0.5 \mathrm{amu}$, Scan, Scan_Bargaph, MiD) from NETZSCH. 
TABLE 1: Specific surface area $\left(S_{\mathrm{BET}}\right)$ and the iron concentration $\left(x_{\mathrm{Fe}}\right)$ in NPs.

\begin{tabular}{lccc}
\hline Sample number & Target composition (pressure $\mathrm{O}_{2}$ ) & $S_{\mathrm{BET}}, \mathrm{m}^{2} / \mathrm{g}$ & $x_{\mathrm{Fe}}, \mathrm{mass} . \%(\mathrm{ICP})$ \\
\hline 1 & $\mathrm{ZnO}-1 \mathrm{wt} . \% \mathrm{Fe}_{2} \mathrm{O}_{3}$ & 44,87 & $0,128 \pm 0,010$ \\
2 & $\mathrm{ZnO}-3 \mathrm{wt} . \% \mathrm{Fe}_{2} \mathrm{O}_{3}$ & 5,23 & $0,619 \pm 0,025$ \\
3 & $\mathrm{ZnO}-5 \mathrm{wt} . \% \mathrm{Fe}_{2} \mathrm{O}_{3}$ & 13,66 & $0,569 \pm 0,023$ \\
4 & $\mathrm{ZnO}-\mathrm{Zn}(4 \mathrm{~Pa})$ & 17 & - \\
5 & $\mathrm{ZnO}(20 \mathrm{~Pa})$ & 12,5 & - \\
6 & $\mathrm{ZnO}(45 \mathrm{~Pa})$ & 24,5 & - \\
\hline
\end{tabular}

TABLE 2: Relative concentrations of the crystalline phases, average values of coherent scattering regions (CSR) in NPs, and lattice parameters of crystalline phases $\mathrm{ZnO}$.

\begin{tabular}{|c|c|c|c|c|c|c|c|}
\hline \multirow{2}{*}{ Sample (pressure) } & \multicolumn{2}{|c|}{$\mathrm{ZnO}(\mathrm{CC})$} & \multicolumn{2}{|c|}{$\mathrm{ZnO}(\mathrm{FC})$} & \multicolumn{2}{|l|}{$\mathrm{Zn}$} & \multirow{2}{*}{$\begin{array}{c}\text { Lattice parameter } \\
\mathrm{ZnO}(\mathrm{FC}), \AA\end{array}$} \\
\hline & Concent., wt.\% & CSR, nm & Concent., wt.\% & CSR, nm & Concent., wt.\% & CSR, nm & \\
\hline $\begin{array}{l}\mathrm{ZnO}-\mathrm{Zn}-\mathrm{Fe} \\
x_{\mathrm{Fe}}=0,619\end{array}$ & 17 & $>200$ & 59 & $\approx 3$ & $24 \%$ & 4,1 & $\begin{aligned} a & =3,239 \pm(4) \\
c & =5,221 \pm(9)\end{aligned}$ \\
\hline $\mathrm{ZnO}-\mathrm{Zn}$ & 9 & $>200$ & 57 & $\approx 3$ & 34 & 10 & $\begin{aligned} a & =3,244 \\
c & =5,246\end{aligned}$ \\
\hline $\mathrm{ZnO}(20 \mathrm{~Pa})$ & - & - & $>95$ & $14,2 \pm 1,3$ & - & - & $\begin{array}{l}a=3,2535 \pm(8) \\
c=5,2252 \pm(30)\end{array}$ \\
\hline $\mathrm{ZnO}(50 \mathrm{~Pa})$ & 17 & $\approx 100$ & 83 & $\approx 8,3$ & - & - & $\begin{array}{l}a=3,245 \\
c=5,223\end{array}$ \\
\hline $\mathrm{ZnO}$-target & & & & & & & $\begin{array}{l}a=3,25 \\
c=5,209\end{array}$ \\
\hline $\begin{array}{l}\text { Reference } \\
\text { standard } \\
\text { PDF-200-001-1136 }\end{array}$ & & & & & & & $\begin{aligned} a & =3,25 \\
c & =5,21\end{aligned}$ \\
\hline
\end{tabular}

\section{Results and Discussion}

3.1. Structural and Element Analysis of Nanopowders. Results of $S_{\mathrm{BET}}$ measurement and the chemical analysis (ICP method) of $\mathrm{NPs} \mathrm{ZnO}, \mathrm{ZnO}-\mathrm{Zn}$, and $\mathrm{ZnO}-\mathrm{Zn}-\mathrm{Fe}$ are given in Table 1. From Table 1, it is visible that the Fe mass content in NP ZnO$\mathrm{Zn}$-Fe does not exceed 1 mass.\% and also does not depend linearly on Fe mass content in precursors (targets). $S_{\mathrm{BET}}$ of NP ZnO-Zn-Fe does not exceed $45 \mathrm{~m}^{2} / \mathrm{g}$. Decrease in $S_{\mathrm{BET}}$ NP with $x_{\mathrm{Fe}}$ growth in targets is caused by strengthening of adhesion NP to glass substrates and formation of coatings on the surface of substrates. Dependence between a mass content of $x_{\mathrm{Fe}}$ dopant and $S_{\mathrm{BET}}$ of NPs is close to the linear.

Previously, in many works [61] it was specified that when using gas-phase methods for producing NPs, irrespective of Fe mass content in targets, the mass content of $x_{\mathrm{Fe}}$ dopant in the final product does not exceed 1 mass $\%$ that will be coordinated in relation to ours by results.

In Table 2 parameters of lattices, relative concentration of crystal phases, and the size of particles are specified in NPs. Essential influence on NP properties puts oxygen pressure in the evaporation camera. With an oxygen pressure in the vaporizing camera of equal (20-50) Pa there was a formation of NP pure $\mathrm{ZnO}$ white color. Synthesized NP contained (1017) mass.\% of coarse-crystalline fraction (CC) $\mathrm{ZnO}$ and (5983) mass.\% of fine-crystalline fraction (FC) ZnO. In all NPs the amorphous phase is found, from trace amounts to a few percents.

Particles of the CC $\mathrm{ZnO}$ can be removed from NPs by means of sedimentation in a liquid phase [60] (e.g., a sedimentary sample of $\mathrm{ZnO}(20 \mathrm{~Pa})$, Table 2).

NPs $\mathrm{ZnO}-\mathrm{Zn}$ and $\mathrm{ZnO}-\mathrm{Zn}-\mathrm{Fe}$ included a significant amount of metal nanoparticles $\mathrm{Zn}$ formed as a result of decomposition $\mathrm{ZnO}$ at high temperature of evaporation in vacuum and had black color. There was a reduction of the FC size of the phase $\mathrm{ZnO}$ as in doped and undoped NPles from $14,3 \mathrm{~nm}$ to $3-4 \mathrm{~nm}$ (Table 2) and considerable change of crystal lattice parameters. The broadening and shift of diffraction peaks in area of small corners in $\mathrm{NP} \mathrm{ZnO}-\mathrm{Zn}-\mathrm{Fe}$ indicate replacement of ions of $\mathrm{Zn}^{2+}$ (ionic radius $0,74 \AA$ ) in $\mathrm{ZnO}$ lattice by $\mathrm{Fe}^{2+}$ ions (ionic radius $0,77 \AA$ ). If the trivalent ion of $\mathrm{Fe}^{3+}$ is built in knots of wurtzite lattice, replacing zinc ions, the parameter of cell has to decrease since for tetrahedral environment the radius of ion of $\mathrm{Fe}^{3+}$ is equal to $0,67 \AA$.

However, we observed significant increase in parameter from wurtzite lattice of $\mathrm{FC} \mathrm{ZnO}$ in the undoped samples received in the oxygen-containing atmosphere with various pressures $(5,2252 \AA(20 \mathrm{~Pa})$ and $5,223 \AA(50 \mathrm{~Pa}))$ and in NP $\mathrm{ZnO}-\mathrm{Zn}$ received in vacuum $(5,246 \AA)$. The parameter growth with FC $\mathrm{ZnO}$ of undoped samples indicates considerable stretching of lattice of samples because of inevitable 


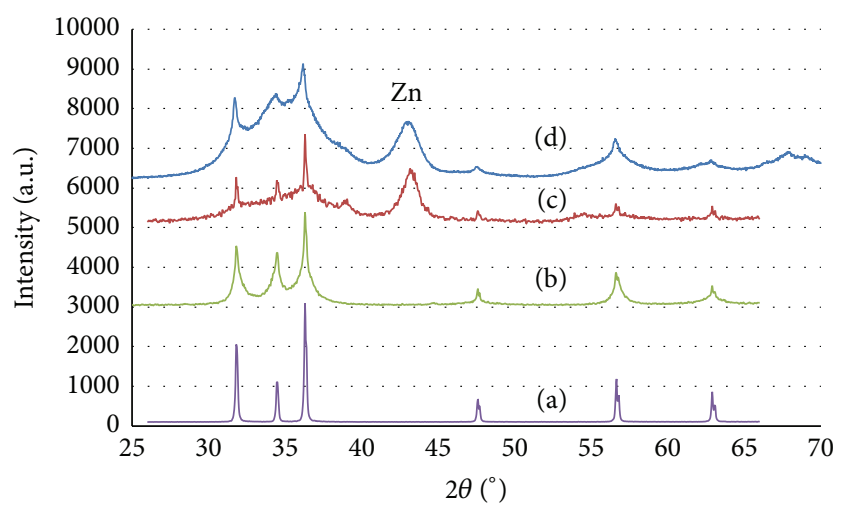

FIGURE 1: XRD pattern of (a) $\mathrm{ZnO}$ submicron powder, (b) $\mathrm{ZnO}$ nanopowder $\left(\mathrm{Po}_{2}=45 \mathrm{~Pa}\right),(\mathrm{c}) \mathrm{NP} \mathrm{ZnO}-\mathrm{Zn}$, and (d) NP ZnO-Zn-Fe $\left(x_{\mathrm{Fe}}=0.619\right.$ wt \%).

formation of oxygen vacancies at evaporation in deficiency of oxygen.

In works [61-64] it is shown that Fe ions in nanomaterials (thin films, various nanostructures, nanopowders, etc.) on the basis of $\mathrm{ZnO}-\mathrm{Fe}$ can be in two- or three-valent condition separately, and in the mixed valent condition, depending on the method and conditions of producing materials. In our case, proceeding from the above changes of crystal structure of $\mathrm{NP} \mathrm{ZnO}-\mathrm{Zn}$-Fe concerning structure of volume $\mathrm{ZnO}$, there was a formation of solid solution of an oxide of $\mathrm{FeO}$ iron in $\mathrm{ZnO}$ on the replacement mechanism; that is, $\mathrm{Fe}^{2+}$ ions were positioned in regular tetrahedral positions of wurtzite lattice.

In Figure 2 SEM/TEM pictures of particles submicronic powder (target) $\mathrm{ZnO}$ and $\mathrm{NPs} \mathrm{ZnO}-\mathrm{Zn}$ and $\mathrm{ZnO}-\mathrm{Zn}-\mathrm{Fe}$ produced by electron beam evaporation in oxygen $(20 \mathrm{~Pa})$ and vacuum are given.

In the submicronic powder $\mathrm{ZnO}$ (pure for analysis) of which targets are made, significant amount of perfect crystalline nanostructures (nanotetrapods, nanorods, etc., Figure 2(a)) is revealed. Narrow, high intensity peaks on XRD pattern of submicronic powder (Figure 1(a)) also confirm its high crystallinity. In Figures 2(b)-2(d) it is visible that all NPs formed during electron evaporation had similar morphology and consisted of the agglomerated NPles with the shape close to spherical, up to $10-20 \mathrm{~nm}$ in size; thus agglomerates were of the nano- and submicronic sizes. Note the existence of significant amount of amorphous particles of an arbitrary shape (Figure 2(d)) and separate core-shell particles (inserts in Figure 2(b) and Figure 2(c)) in NPs.

Quantitative EDX analysis from several local areas of sample $\mathrm{ZnO}-\mathrm{Zn}-\mathrm{Fe}\left(x_{\mathrm{Fe}}=0.619\right.$ mass.\%, ICP $)$ showed considerable dispersion on concentration of $\mathrm{Fe}$ (from 0.17 up to 3 mass. $\mathrm{Fe} \%$ ) and lack of other impurity elements in sample. Results of EDX analysis from sample area (it is shown on Figure 3 insert) by $\mathrm{ZnO}-\mathrm{Zn}-\mathrm{Fe}$ are given in Figure 3. Red color shows spectral lines from the copper grid.

Distribution of elements $\mathrm{O}, \mathrm{Fe}$, and $\mathrm{Zn}$ on several areas of the sample $\mathrm{ZnO}-\mathrm{Zn}$-Fe (Figure 4(a)) is qualitatively estimated by means of EDX mapping by the STEM method (Figures 4(b)-4(d)). Mapping showed uniform distribution of atoms $\mathrm{O}$ and $\mathrm{Zn}$. However, distribution of atoms $\mathrm{Fe}$ (Figure 4(d)) is less uniform. In Figure 4(d) the tendency to formation of curved "chains" atoms can be observed. Formations of visible congestions from atoms $\mathrm{Fe}$ (Fe clusters) are not observed. In Figure 4(e) there is EDX range of the sample $\mathrm{ZnO}-\mathrm{Zn}-\mathrm{Fe}$ where it is presented that the sample generally contains atoms $\mathrm{Zn}$ and $\mathrm{O}$, with trace quantity (and trace) of the Fe element. On an insert of Figure 4(e) it is shown that the concentration of $\mathrm{Fe}$ in this sample was about 0.17 mass.\%.

3.2. Magnetic Properties and Phase Transformations of NPs. For the purpose of receiving NPs $\mathrm{ZnO}-\mathrm{Zn}$ with the minimum content of parasitic impurity, we carried out powder deposition on a glass substrate. Target material from the submicronic powder $\mathrm{ZnO}$ previously was checked on Faraday's scales. Results of measurements showed the existence of weak ferromagnetic response in submicron powder $(1,5 *$ $10^{-3} \mathrm{emu} / \mathrm{g}$ ) connected, either with impurity or with presence at powder quantity of perfect nanostructures (nanotetrapods and nanorods, Figure 2(a), are shown by shooters) which, as we know, possess their own RTFM [35, 41, 43].

The increased magnetization of $\mathrm{NP} \mathrm{ZnO}-\mathrm{Zn}$ besieged on metal substrates most likely was caused by the impurity formed in powders owing to the reverse diffusion of substrates elements at high-temperature deposition.

Curves of magnetization $(M)$ are given in Figure 5 at the room temperature for $\mathrm{NP} \mathrm{ZnO}-\mathrm{Zn}$ ( 34 mass.\% $\mathrm{Zn}$ ) from a glass substrate in a magnetic field $12 \mathrm{kOe}$.

$\mathrm{NP} \mathrm{ZnO}-\mathrm{Zn}$ showed a weak ferromagnetic response at room temperature, equal to $7 * 10^{-3} \mathrm{emu} / \mathrm{g}$.

The growth of magnetization of sample $\mathrm{ZnO}-\mathrm{Zn}$ after short-term annealing in the air atmosphere (temperature of annealing of $300^{\circ} \mathrm{C}$, time of annealing of $30 \mathrm{~min}$.) appeared to be unexpected; magnetization of the annealed sample grew to $9,5 * 10^{-3} \mathrm{emu} / \mathrm{g}$

Note that the growth of magnetization NPles of pure $\mathrm{ZnO}$ after annealing in the oxidizing atmosphere is observed in work [65]; the growth of magnetization is explained with formation of clusters from oxygen vacancies. In our case, it is the most probable that the growth of magnetization was caused by a process of phase transformation (oxidation) of NPles $\mathrm{Zn}$ in $\mathrm{ZnO}$ oxide when annealing. Considering the small duration and low temperature of annealing, we do not exclude that the process of oxidation $\mathrm{Zn}$ to $\mathrm{ZnO}$ took place not completely that could lead to formation of some quantity of core-shell structures of $\mathrm{ZnO}-\mathrm{Zn}$ (a diamagnetic core from $\mathrm{Zn}$ and a shell from amorphous $\mathrm{ZnO}$ ). The example such of a core-shell structure in NP ZnO-Zn is shown on Figure 2(b) insert. It is probable that the process of oxidation of NPles $\mathrm{Zn}$ and forming of core-shell structures leads to increase of the concentration of oxygen vacancies in the annealed sample that was reflected in magnetization growth.

Note the increase of diamagnetic contribution to the specific magnetization of sample $\mathrm{ZnO}-\mathrm{Zn}$ in magnetic field higher than $7 \mathrm{kOe}$. Thus, strengthening of magnetization NP $\mathrm{ZnO}-\mathrm{Zn}$ after annealing can be caused by a number of factors: formation of amorphous layers on borders between $\mathrm{ZnO}$ 


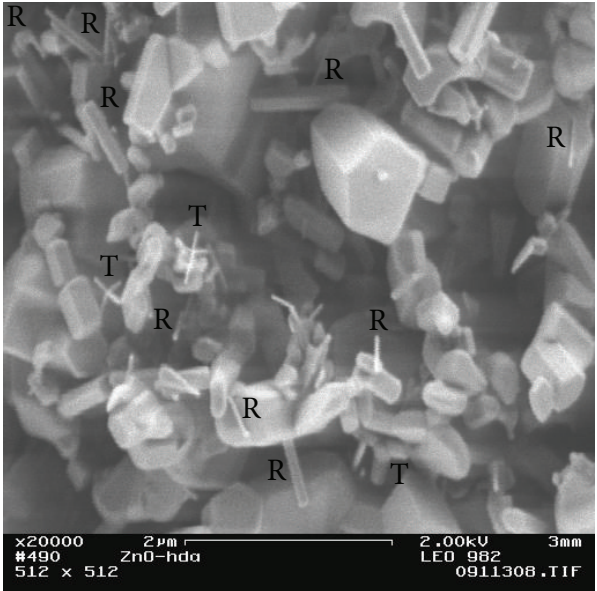

(a)

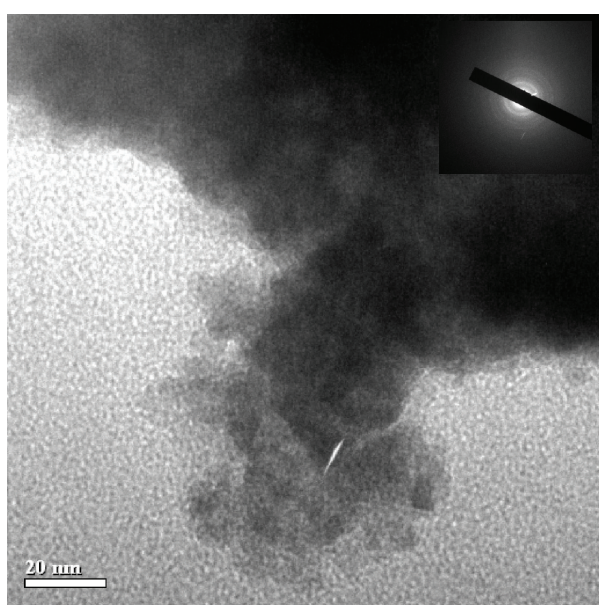

(c)

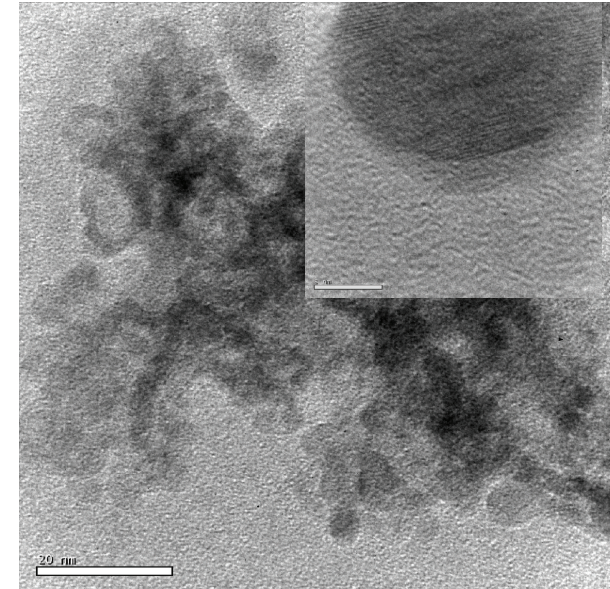

(b)

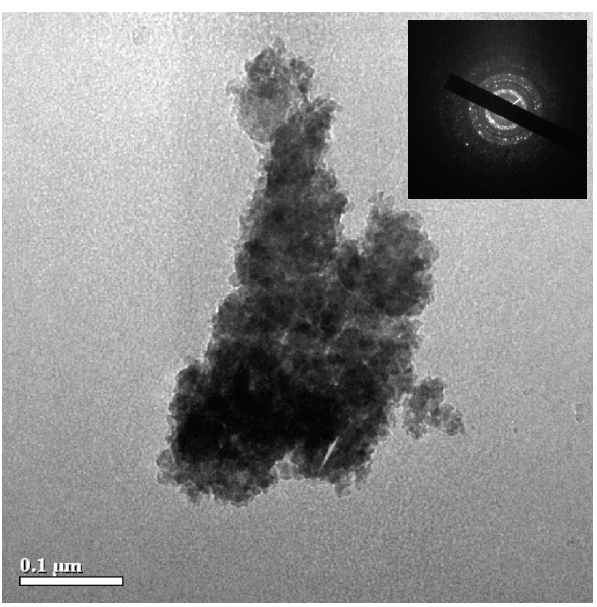

(d)

FIGURE 2: (a) SEM picture of particles of submicronic powder (target) ZnO (designation: T, nanotetrapods; R, nanorods); (b) TEM NP ZnO$\mathrm{Zn}$ picture (on the insert, core-shell nanoparticle $\mathrm{ZnO}$ with amorphous shell); (c) TEM picture NP ZnO-Zn-Fe (on the insert, the electron diffraction pattern from the amorphous area of sample); (d) TEM picture of agglomerate nanoparticles $\mathrm{ZnO}-\mathrm{Zn}$-Fe (on the insert, the electron diffraction pattern from the crystalline area of sample).

nanoparticles, generation of core-shell structures with the broken stoichiometry on the interface between core and shell, and clustering of oxygen vacancies.

In particular, emergence of ferromagnetic properties in films of pure $\mathrm{ZnO}$ at the expense of formation of foamlike grid from amorphous $\mathrm{ZnO}$ between NPles is shown in Straumal's numerous works [11] and correlates with our data.

Besides, the number of experimental works accruing every year much more confirms that carriers of a charge are not so necessary for RTFM emergence; in particular, ferromagnetic interaction is observed in films without free carriers in a dielectric condition [10, 66-71]. In our case, after annealing of conducting NP $\mathrm{ZnO}-\mathrm{Zn}$ as a result of oxidation of NPles $\mathrm{Zn}$ the number of free carriers sharply decreased (powder turned into dielectric) that directly correlates with conclusions [10, 66-71]. The growth of magnetization of NP $\mathrm{ZnO}-\mathrm{Zn}$ after annealing proves that the role of free carriers in RTFM formation in annealed NP $\mathrm{ZnO}-\mathrm{Zn}$ is insignificant.
Note works $[72,73]$ where the inverse correlation between magnetization and electronic density was shown.

In Figure 6 magnetization curves are given at the room temperature of NP $\mathrm{ZnO}-\mathrm{Zn}-\mathrm{Fe}\left(x_{\mathrm{Fe}}=0.128,0.569,0.619\right.$ mass.\%) in a magnetic field $12 \mathrm{kOe}$ [59].

From Figure 6 it follows that dependence of the magnetic moment on atom of $\mathrm{Fe}\left(\mu_{\mathrm{B}} / \mathrm{Fe}\right)$ from $x_{\mathrm{Fe}}$ in NP $\mathrm{ZnO}-\mathrm{Zn}-\mathrm{Fe}$ is nonlinear. The maximum magnetic moment $\left(0,272 \mu_{\mathrm{B}} / \mathrm{Fe}\right)$ is determined in NPs at an intermediate concentration of $x_{\mathrm{Fe}}=0,569$ mass. $\%$ that confirms, noted above, lack of direct correlation between magnetization and concentration of iron magnetic ions in powders and will be coordinated with conclusions $[10-13,71]$.

In particular, authors of the work [11] connect ferromagnetism of $\mathrm{ZnO}$ not with entered ions of transitional metals but with the magnetic moments in vacancies of lattice which concentrate on borders of grains. Therefore, the introduction of ions Fe probably only promotes emergence (strengthening) 


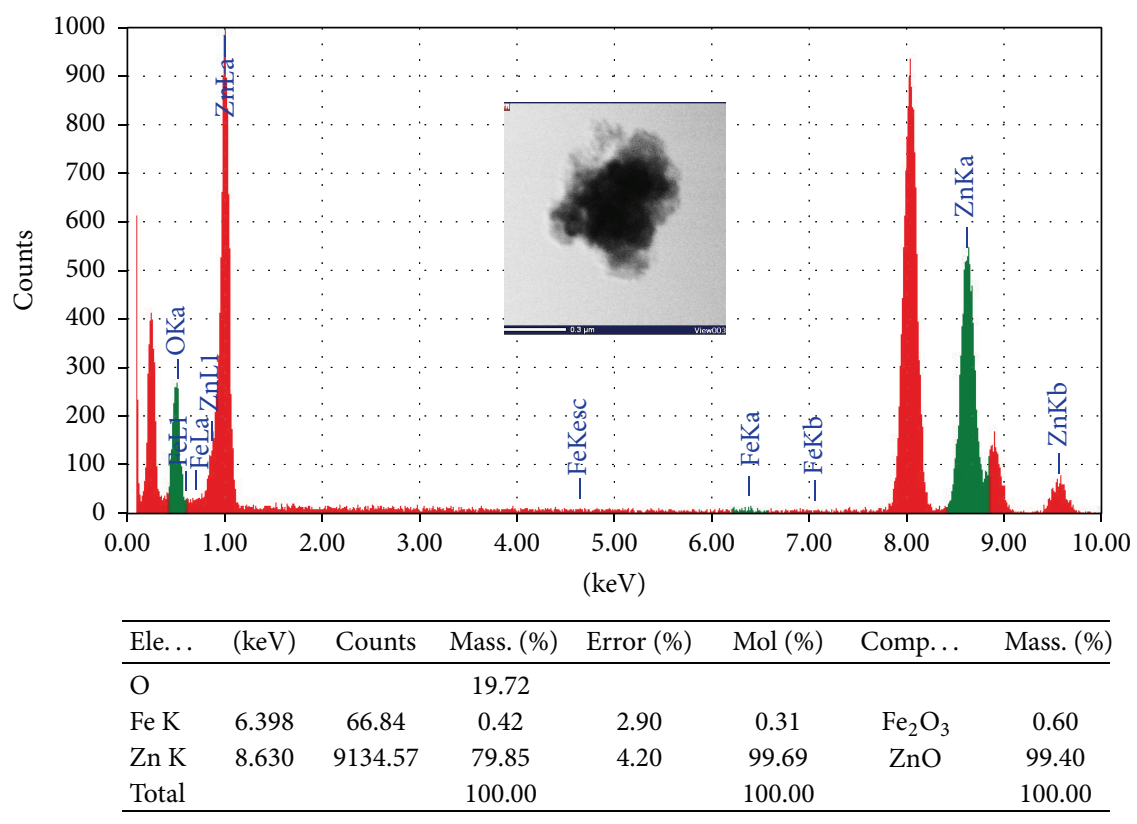

Figure 3: EDX spectra of sample ZnO-Zn-Fe ( $x_{\mathrm{Fe}}=0.619$ mass.\% (ICP)).

of ferromagnetism in NP $\mathrm{ZnO}-\mathrm{Zn}-\mathrm{Fe}$ due to emergence of noncoupled spins $\mathrm{Fe}^{2+}\left(\mathrm{Fe}^{3+}\right)$ ions and to increase in disorder and defectiveness of NP structure at doping (that confirms corresponding change of $\mathrm{ZnO}-\mathrm{Zn}$-Fe lattice parameters).

Further increase in concentration of Fe in NP ZnO-ZnFe with 0,569 up to 0,619 mass.\% led to decrease in magnetic response. Decrease in magnetization shows that magnetization of NP is not connected with possible formation of secondary phases and type of clusters $\mathrm{Fe}, \mathrm{Fe}_{3} \mathrm{O}_{4}$, or $\gamma$ - $\mathrm{Fe}_{2} \mathrm{O}_{3}$. If pure $\mathrm{Fe}$ or its oxides were responsible for ferromagnetic behavior of NP, the increase in concentration of $x_{\mathrm{Fe}}$ in samples would lead to an increase in a volume fraction of these phases in samples and the related magnetic response.

Magnetization curves of samples with $x_{\mathrm{Fe}}=0,569$ and 0,619 mass.\% did not reach saturation in the magnetic field to $12 \mathrm{kOe}$. That points at strengthening of paramagnetic contribution to magnetization. Strengthening of antiferromagnetic interaction between the neighboring $\mathrm{Fe}-\mathrm{Fe}$ ions suppresses ferromagnetism at high concentration of $\mathrm{Fe}$. In particular, the similar behavior was traced in $\mathrm{ZnO}-\mathrm{Fe}$ NPles in [74], where with $x_{\mathrm{Fe}}$ growth up to 20 at.\% the increase of paramagnetic contribution occurred. Note that, in [74] with the comparable sizes of particles, our NPles had magnetization of nanoparticles 10 times less which can be explained by smaller concentration of the defects formed during the chemical method.

It is known [75] that creation of effective exchange interaction between magnetic ions in DMS requires rather high concentrations of dopant (usually units\%), with rare exception $[10,76]$. In our NPs concentrations of magnetic dopant were 10 times less than the threshold that directly specifies that the mechanism of observed ferromagnetism is not defined by short-range exchange interaction between magnetic ions of dopant, improbable because of long distances between ions, and is more connected with defects of various types which were formed in NPles as a result of nonequilibrium crystallization of NPles with high temperature on cold glass substrates.

In addition, the question of the ferromagnetism nature in heterophase NP $\mathrm{ZnO}-\mathrm{Zn}-\mathrm{Fe}$ complicates the existence of amorphous components in NP detected from XRD and the microscopic analysis. Influence of dimensional factor on magnetization of NPs from the fine-crystalline phases $\mathrm{ZnO}$ and $\mathrm{Zn}$ is not excluded.

After annealing of the conductive $\mathrm{ZnO}-\mathrm{Zn}$-Fe nanopowder, as a result of the oxidation of $\mathrm{Zn}$ nanoparticles the powder transformed into a dielectric. In such NPs density of electric carriers is low that excludes a possible explanation of ferromagnetism in NPs $\mathrm{ZnO}-\mathrm{Fe}$ using the carrier-mediated exchange mechanism.

In Figure 7 magnetization curves of NPs $\mathrm{ZnO}-\mathrm{Fe}\left(x_{\mathrm{Fe}}=\right.$ $0.128,0.569,0.619$ mass.\%), received on the vibration magnetometer in magnetic fields $\pm 1 \mathrm{~T}$ are given at the room temperature. Note the considerable strengthening of samples $\mathrm{ZnO}-\mathrm{Fe}$ magnetization in comparison with magnetization of nonannealed NPs $\mathrm{ZnO}-\mathrm{Zn}$-Fe. Magnetization of samples with concentration of $x_{\mathrm{Fe}}=0.128,0.569,0.619$ mass.\% grew by $\approx 5,2.5$, and 2 times, respectively. Strengthening of magnetization of undoped sample $\mathrm{ZnO}-\mathrm{Zn}$ after annealing (Figure 4) was much less (35\%) that is possible to explain with non-full oxidation of NPles $\mathrm{Zn}$ to $\mathrm{ZnO}$ at lower temperature of annealing $\left(300^{\circ} \mathrm{C}\right)$ and small time of annealing $(30 \mathrm{~min}$.).

Note that the magnetization of our samples is 10 times more than magnetization of samples $\mathrm{ZnO}-\mathrm{Fe}$ with close concentration of dopant $(\leq 1 \%)$ received with use of traditional ceramic synthesis ( $x_{\mathrm{Fe}}$ of $=1 \%, M_{S}=1,25 * 10^{-2} \mathrm{emu} / \mathrm{g},[42]$ ), 


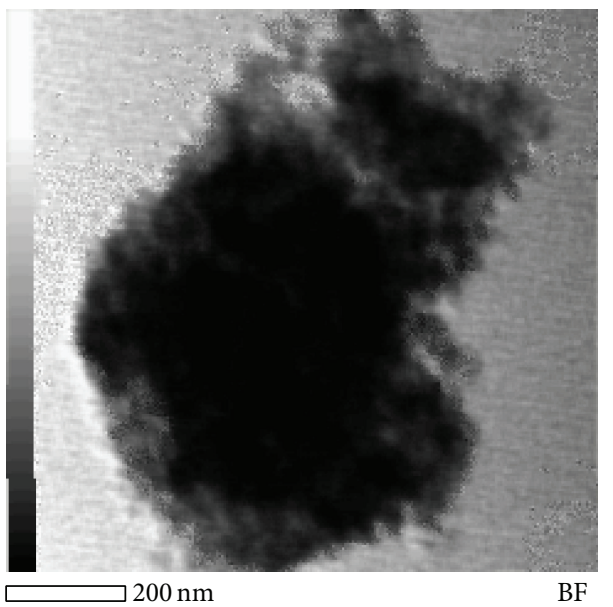

(a)

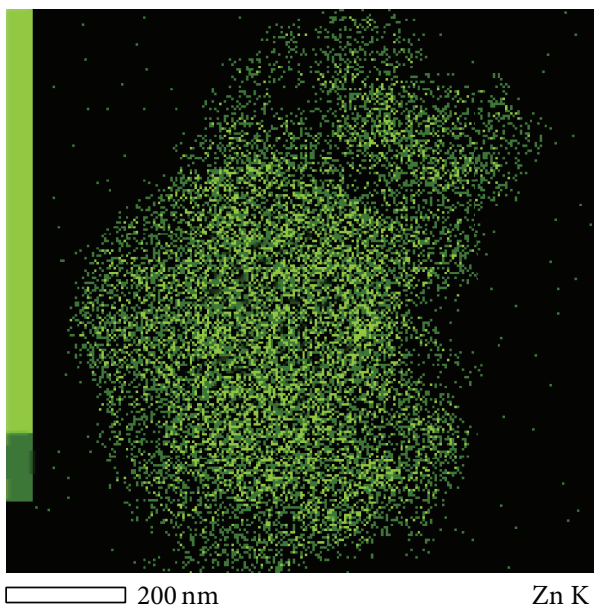

(c)

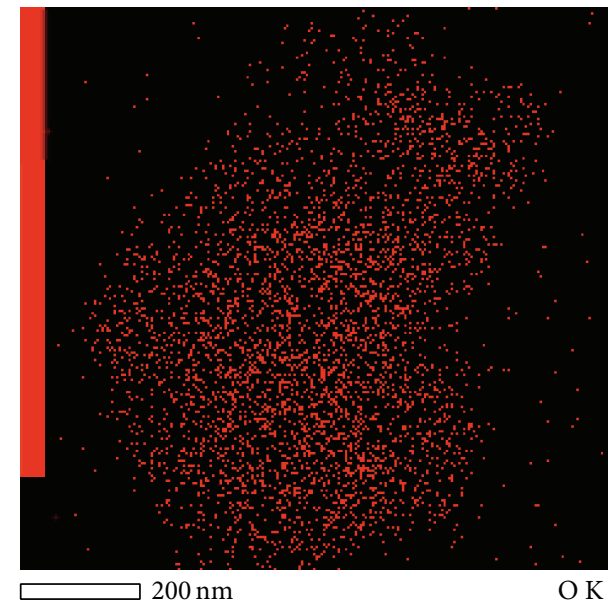

(b)

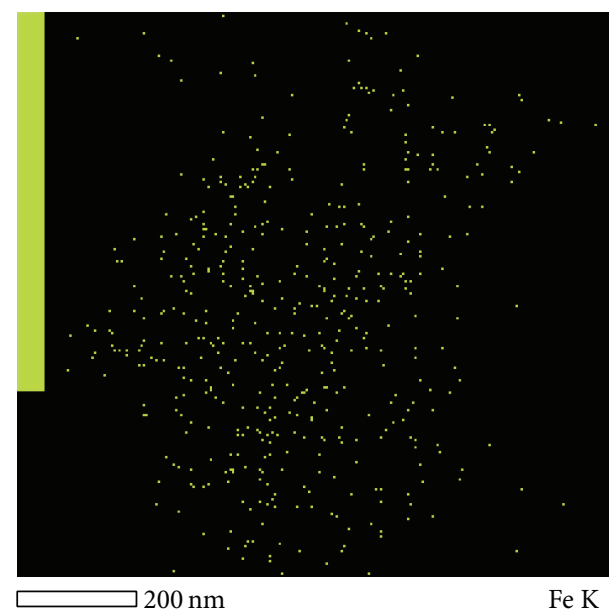

(d)

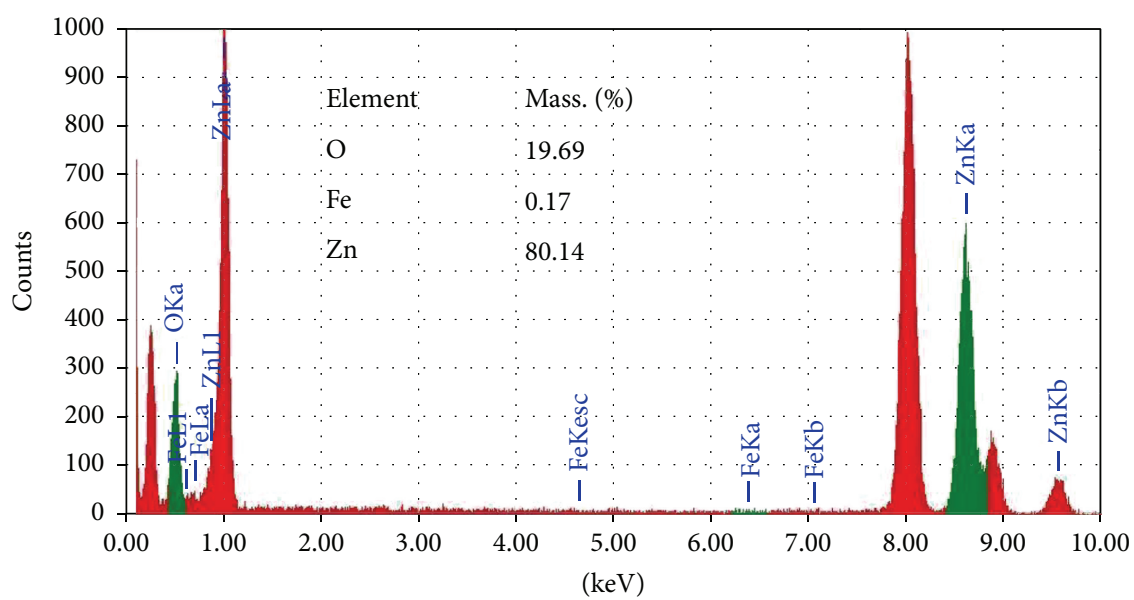

(e)

FiguRE 4: (a) STEM image of ZnO-Zn-Fe sample; (b), (c), (d) the corresponding EDX mappings of O, Zn and Fe; (e) EDX spectra of sample $\mathrm{ZnO}-\mathrm{Zn}-\mathrm{Fe}$. 


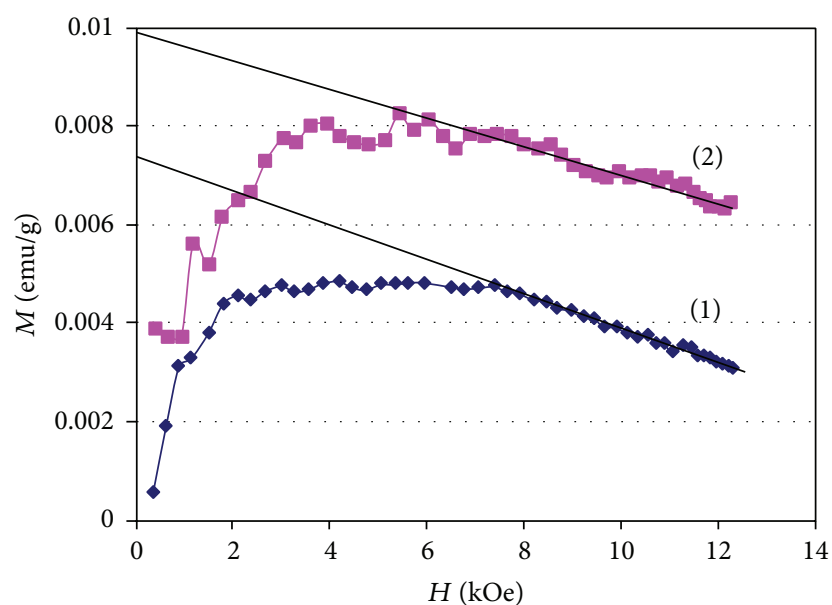

Figure 5: Room temperature $M-H$ curves for $\mathrm{ZnO}-\mathrm{Zn}$ NP: (1) as prepared and (2) after annealing.
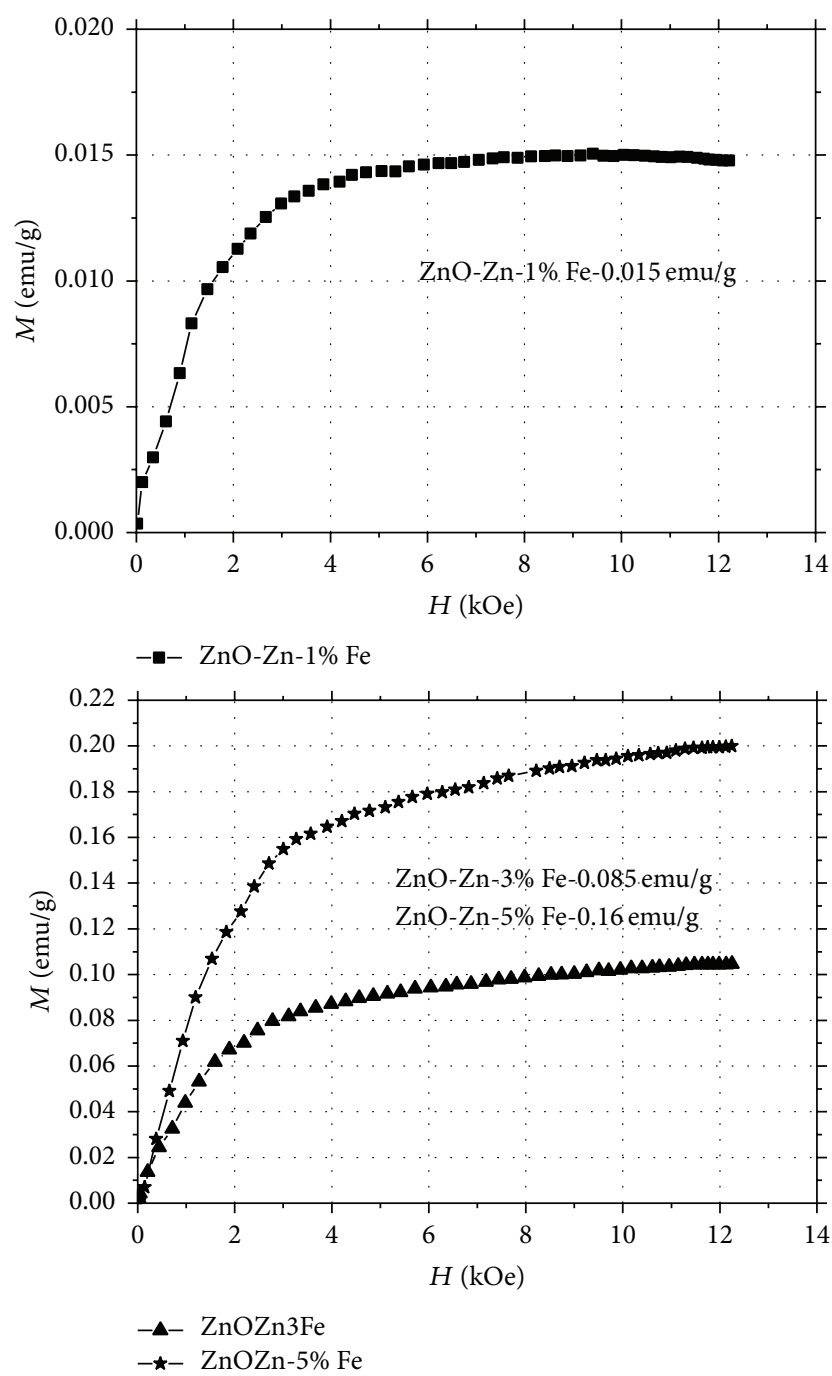

FIGURE 6: Magnetization change at room temperature in NP ZnO$\mathrm{Zn}-\mathrm{Fe}$ in relation to concentration of $\mathrm{Fe}$.

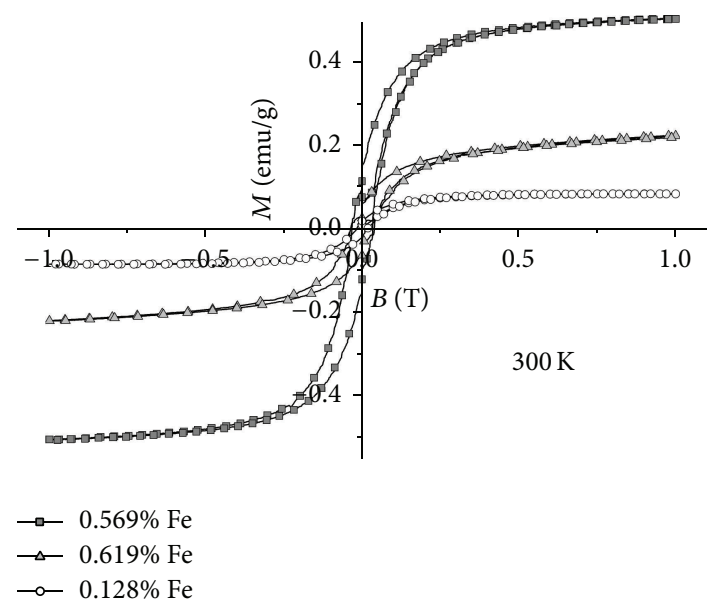

Figure 7: $M$ versus $H$ curves for $\mathrm{ZnO}-\mathrm{Zn}-\mathrm{Fe}$ NPs with various doping concentrations.

method sol-gel [28]) that obviously points to a defining role of structural defects on strengthening of ferromagnetic response and preference of use of strongly nonequilibrium methods for formation of structural defects in various materials, before methods of wet chemistry.

The general nature of magnetization change of samples $\mathrm{ZnO}-\mathrm{Fe}$ from a concentration of $\mathrm{Fe}$ remained the same, as with nonannealed samples of $\mathrm{ZnO}-\mathrm{Zn}-\mathrm{Fe}$. All samples of $\mathrm{ZnO}-\mathrm{Fe}$ showed RTFM and had well-defined hysteresis with coercive force in the range from 160 to 380 Oe. Thus, the sample with $x_{\mathrm{Fe}}=0.128 \%$ was completely saturated in the magnetic field $\pm 1 \mathrm{~T}$ though curves magnetizing is exemplary with $x_{\mathrm{Fe}}=0.569$ and 0.619 continued to grow with increase in the magnetic field and did not come for saturation. Similar change of magnetization curves with growth of a dopant concentration quite often has been observed in $\mathrm{ZnO}$ Fe system before $[28,77,78]$. Note that the hysteresis loop measured on the $\mathrm{ZnO}$-Fe sample $(0.128 \%)$ is thinner than those measured on the other samples.

The broadening of hysteresis loops is caused by the fact that with the growth of dopant concentration the average distance between ions of Fe decreases (see Table 2) and antiferromagnetic exchange energy of ions $\mathrm{Fe}$ becomes less than ferromagnetic exchange energy; therefore the magnetic moments of ions $\mathrm{Fe}$ are ordered antiferromagnetically that reduces magnetism of samples [79].

Now, in the theory of ferromagnetism DSM two models [10] connected with a charge transfer and with the formation of the connected magnetic polarons dominate.

The ferromagnetism nature in NPs $\mathrm{ZnO}$-Fe received can be explained using the model of the connected magnetic polarons [80].

Polarons are in a low-doped sample $(0.128 \%$ of $\mathrm{Fe})$ at rather long distances from each other to carry out strong exchange interaction. Apparently, in a sample with a concentration of dopant of equal 0.519 mass.\%, the distance between the neighboring polarons decreases and becomes optimum; therefore, the exchange between two neighboring magnetic polarons amplifies. It is possible that in a more 
strongly doped sample $\left(x_{\mathrm{Fe}}=0.619\right)$ the magnetic moment quickly decreased due to strengthening of dopant-dopant associations that brought progressive reduction of the orbital moment. Reduction of the magnetic moment in NPs $\mathrm{ZnO}-\mathrm{Fe}$ with the growth of concentration Fe also indirectly confirms lack of the secondary magnetic phases Fe in the sample and is consistent with the XRD data. Consider the following:

(A) Similar picture of magnetization strengthening samples after annealing as in NPs $\mathrm{ZnO}-\mathrm{Zn}$ and $\mathrm{ZnO}-\mathrm{Zn}$ $\mathrm{Fe}$, observed earlier in $\mathrm{ZnO}-\mathrm{Zn}-\mathrm{Cu}$ system $\left(300^{\circ} \mathrm{C}\right.$, time of annealing of 30 minutes) [81].

(B) Magnetization growth in undoped Fe NPs $\mathrm{ZnO}-\mathrm{Zn}$ and $\mathrm{ZnO}-\mathrm{Zn}-\mathrm{Cu}$ (the content of Fe impurity in the above samples according to ICP of the analysis did not exceed $10^{-3}-10^{-2}$ mass. $\mathrm{Fe} \%$ that is $1-2$ orders less than concentration of ions $\mathrm{Fe}$ in NPs $\mathrm{ZnO}-\mathrm{Fe}$ $(\mathrm{ZnO}-\mathrm{Zn}-\mathrm{Fe})$ directly specifies that the ferromagnetic response is not connected with magnetic ions Fe.

(C) It is the most probable that, when annealing NPs $\mathrm{ZnO}-\mathrm{Zn}$ and $\mathrm{ZnO}-\mathrm{Zn}-\mathrm{Cu}$ as the result of NPles $\mathrm{Zn}$ oxidation to NPles $\mathrm{ZnO}$, recrystallization of NPles, partial crystallization of amorphous fraction, generation of core-shell structures (the core- $\mathrm{Zn}$, the shall-ZnO), the concentration of various structural defects (oxygen vacancies, cation vacancies, interstitial atoms, dislocation, etc.) in NPs changed in a complex manner, which led to strengthening of magnetization samples.

Dynamic heating of sample $\mathrm{ZnO}-\mathrm{Zn}$-Fe in the air atmosphere using the DSC-TG method also showed (Figure 8(b), curve TG) that full oxidation of nanoparticles $\mathrm{Zn}$ comes to the end at temperature $\approx 600^{\circ} \mathrm{C}$ that in addition confirms the possibility of preservation of core-shell structures in powder at short-term annealing at the temperature of $500^{\circ} \mathrm{C}$.

Oxidation of NPles $\mathrm{Zn}$ in NP $\mathrm{ZnO}-\mathrm{Zn}-\mathrm{Fe}$ began from temperature $\approx 200^{\circ} \mathrm{C}$ (exothermic peak 1 at curve TG in Figure $8(\mathrm{~b})$ ) which is slightly higher than the temperature of the oxidation beginning $\mathrm{NP} \mathrm{ZnO}-\mathrm{Zn}$ equal to $110^{\circ} \mathrm{C}$ (Figure 8(a), curve TG). Thus, $\mathrm{Fe}$ introduction in $\mathrm{ZnO}$ inhibits temperature of the oxidation beginning of NPles $\mathrm{Zn}$ and reduces the speed of oxidation reaction NPles $\mathrm{Zn}$ in doped powder. Oxidation of NPles $\mathrm{Zn}$ comes to the end in NP $\mathrm{ZnO}-\mathrm{Zn}$ (curve TG, Figure 8(a)) and $\mathrm{ZnO}-\mathrm{Zn}$ $\mathrm{Fe}$ (curve TG, Figure $8(\mathrm{~b})$ ) at temperatures of $\approx 280^{\circ} \mathrm{C}$ and $600^{\circ} \mathrm{C}$, respectively.

In our opinion, the new model of ferromagnetism is the most suitable one for an explanation of the nature of RTFM in systems $\mathrm{ZnO}-\mathrm{Zn}$ and $\mathrm{ZnO}-\mathrm{Zn}-\mathrm{Fe}(\mathrm{Cu})$ in the diluted magnetic oxides (charge-transfer ferromagnetism model), offered by Coey et al. [82] which is based on the Stoner type of ferromagnetism connected with electrons in percolation defective structures, such as the grain boundaries.

This model has successfully been applied to an explanation of ferromagnetic interaction in NPles of semiconductor oxides and doped ions of transitional metals in the mixed valent state [10, 83]. In particular, charge-transfer ferromagnetism model has been used for RTFM explanation in objects

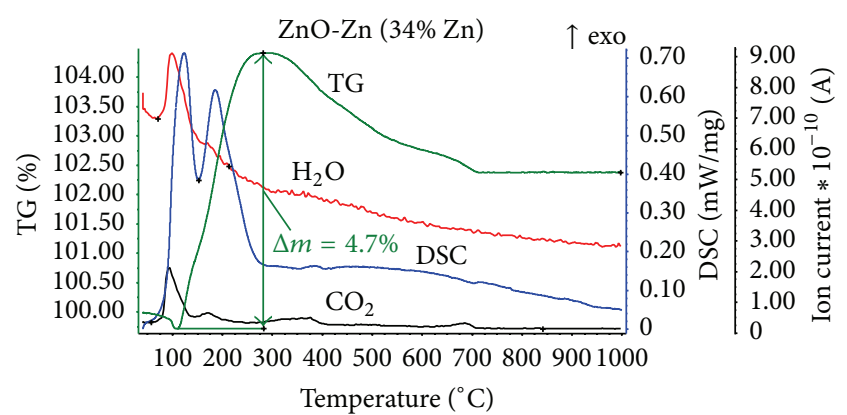

(a)

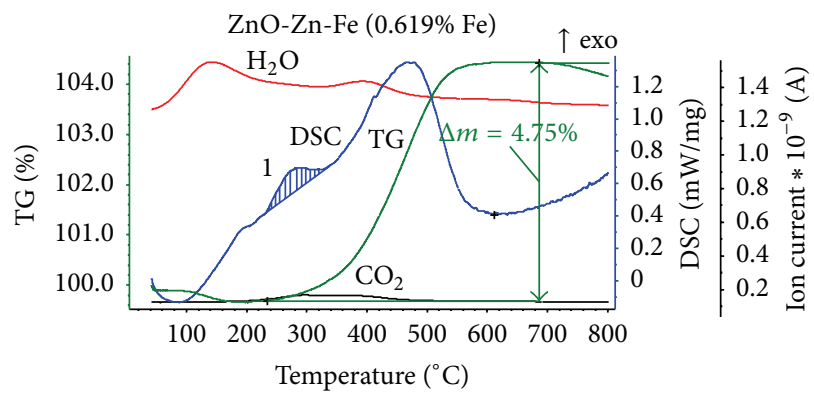

(b)

FIGURE 8: Heating thermograms DSC-TG and the mass spectra $\mathrm{H}_{2} \mathrm{O}$ and $\mathrm{CO}_{2}$ of the NPs $\mathrm{ZnO}-\mathrm{Zn}$ (a) and $\mathrm{ZnO}-\mathrm{Zn}-\mathrm{Fe}(\mathrm{b})$.

films of $\mathrm{Zn}_{x} \mathrm{ZnO}_{1-x}$ close to our NP [84] and core-shell $\mathrm{Zn} / \mathrm{ZnO}$ [85] structures. Besides the model does not assume homogeneous distribution of magnetic dopant on the sample that in the best way approaches the situation (Figure 4(c)).

Thus, we showed that magnetism of low-doped $\left(x_{\mathrm{Fe}} \leq\right.$ 0,619 wt.\%) and undoped Fe NPs on the basis of $\mathrm{ZnO}$ is their intrinsic property. The dominating contribution to ferromagnetism of samples is made by various structural defects (oxygen vacancies, interstitial atoms of introduction, and amorphous component), instead of charge carriers.

It is determined that there is nonlinear dependence of magnetization on concentration of magnetic dopant in NP $\mathrm{ZnO}-\mathrm{Zn}-\mathrm{Fe}$ and $\mathrm{ZnO}-\mathrm{Fe}$. The maximum magnetic moment in samples of $\mathrm{ZnO}-\mathrm{Zn}-\mathrm{Fe}$ and $\mathrm{ZnO}-\mathrm{Fe}$ is observed at concentration of magnetic dopant equal to $0,519 \mathrm{wt} . \%$ which is much lower than a percolation threshold.

The received results will be coordinated with Pan et al. [10] given the review where it is shown that the maximum magnetic moment in $\mathrm{ZnO}-\mathrm{Fe}$ systems $(\mathrm{Cu}, \mathrm{Cr}, \mathrm{Ni})$ is usually observed at concentration of dopant $\approx 1$ at.\%. However, further work on ferromagnetism studying of the zinc oxide alloyed by $\mathrm{Fe}$ is required. It will be oriented to the establishment of an unambiguous correlation between defectiveness of structure and magnetic properties and the identification of defects in their nature and the mechanism of their interaction leading to the emergence of ferromagnetism at the room temperature.

\section{Conclusions}

With the help of evaporation the pulsed electron beam in vacuum and oxygen $\mathrm{NPs} \mathrm{ZnO}, \mathrm{ZnO}-\mathrm{Zn}$, and $\mathrm{ZnO}-\mathrm{Zn}-\mathrm{Fe}$ was 
received. The specific surface area of samples did not exceed $45 \mathrm{~m}^{2} / \mathrm{g}$. The bimodal distribution of the phase $\mathrm{ZnO}$ with wurtzite structure on fractions and existence of amorphous components in all NPs without any exception is shown. All powders possessing similar morphology are agglomerated (in agglomerates of the nano and submicronic sizes) and have the shape of particles close to spherical being not over $20 \mathrm{~nm}$ in size. The data of electronic microscopy confirm the existence of core-shell structures with a metal core $\mathrm{Zn}$ and an amorphous oxidic shell in powders. The concentration of Fe in samples was less than 0,619 wt.\% that is much lower than the percolation threshold. By means of mapping rather uniform distribution of $\mathrm{Fe}$ in $\mathrm{ZnO}$ lattice was established.

Doped and undoped iron NPs on the basis of $\mathrm{ZnO}$ showed RTFM which considerably (4-fold growth at the sample with the minimum concentration of dopant) increased after NP annealing in the air. The growth of magnetization is caused by phase transformation (oxidation of nanoparticles $\mathrm{Zn}$ to $\mathrm{ZnO}$ ) and formation of additional structural defects (generally oxygen vacancies) when annealing.

The inhibiting influence of a doped Fe on temperature of the beginning of nanoparticles of $\mathrm{Zn}$ oxidation and decrease in speed of oxidation reaction in nanoparticles $\mathrm{Zn}$ in doped powder in comparison with $\mathrm{NP} \mathrm{ZnO}-\mathrm{Zn}$ are established.

The lack of logical correlation between the magnetic moment and concentration of dopant iron in NP ZnO-Zn-Fe and $\mathrm{ZnO}-\mathrm{Fe}$ is shown. The mechanism of RTFM emergence in the samples containing metal particles of $\mathrm{Zn}$ can be explained by means of the charge-transfer ferromagnetism model in the diluted magnetic oxides. For RTFM explanation in the annealed samples of $\mathrm{ZnO}-\mathrm{Fe}$ with a lowered density of electric carriers the model of the connected magnetic polarons is more suitable.

\section{Additional Points}

The authors prepared undoped and Fe-doped $\mathrm{ZnO}$ nanopowders by the pulsed electron beam evaporation method:

(i) They studied the structural, morphological, and magnetic properties in detail.

(ii) Fe-doped $\mathrm{ZnO}$ samples exhibited ferromagnetic behavior at room temperature.

(iii) Magnetization growth of NPs $\mathrm{ZnO}-\mathrm{Zn}$ and $\mathrm{ZnO}-\mathrm{Zn}$ Fe was detected after their short-term annealing on air.

(iv) The effects of Fe content on magnetic properties of Fedoped $\mathrm{ZnO}$ nanopowders were investigated.

\section{Competing Interests}

The authors declare that they have no competing interests.

\section{Acknowledgments}

The authors are grateful to the employee of IPM of the Ural Branch of the Russian Academy of Sciences (UB RAS), Uimin M. A., and to the employee of IMET UB RAS, Uporov S. A., for discussion and measurement of magnetic characteristics, to the employee of center for collective use "Ural" of IMET UB RAS, Pryanichnikov S. V., for XRD analysis, and to the employee of IEP UB RAS, Demina T. M., for the measurement of $S_{\mathrm{BET}}$ and DSC-TG analysis. The research is performed with partial support of projects by the Russian Foundation for Basic Research no. 15-08-01381, no. 12-03-31593-mol-a, and no. 13-03-00119-a and Presidium Ural Branch Russian Academy of Sciences and Sverdlovskaya Oblast Government (no. 13-08-96056 P_URAL_a, no. 12-M-23-2007, and no. 12-TZ-1009) and Grant ERA.NET RUS Plus, S\&T (NanoRadDos).

\section{References}

[1] J. M. D. Coey and S. A. Chambers, "Oxide dilute magnetic semiconductors-fact or fiction?" MRS Bulletin, vol. 33, no. 11, pp. 1053-1058, 2008.

[2] T. Dietl, "A ten-year perspective on dilute magnetic semiconductors and oxides," Nature Materials, vol. 9, no. 12, pp. 965-974, 2010.

[3] H. Ohno, "A window on the future of spintronics," Nature Materials, vol. 9, no. 12, pp. 952-954, 2010.

[4] R. Singh, "Unexpected magnetism in nanomaterials," Journal of Magnetism and Magnetic Materials, vol. 346, pp. 58-73, 2013.

[5] R. B. Morgunov and A. I. Dmitriev, "Spin dynamics in magnetic semiconductor nanostructures," Physics of the Solid State, vol. 51, p. 1985, 2009.

[6] T. Dietl, H. Ohno, F. Matsukura, J. Cibert, and D. Ferrand, "Zener model description of ferromagnetism in zinc-blende magnetic semiconductors," Science, vol. 287, no. 5455, pp. 10191022, 2000.

[7] K. Sato and H. Katayama-Yoshida, "Electronic structure and ferromagnetism of transition-metal-impurity-doped zinc oxide," Physica B: Condensed Matter, vol. 308-310, pp. 904-907, 2001.

[8] S. J. Pearton, D. P. Norton, M. P. Ivill et al., "Ferromagnetism in transition-metal doped ZnO," Journal of Electronic Materials, vol. 36, no. 4, pp. 462-471, 2007.

[9] C. Liu, F. Yun, and H. Morkoç, "Ferromagnetism of $\mathrm{ZnO}$ and GaN: a review," Journal of Materials Science: Materials in Electronics, vol. 16, article 555, 2005.

[10] F. Pan, C. Song, X. J. Liu, Y. C. Yang, and F. Zeng, "Ferromagnetism and possible application in spintronics of transitionmetal-doped ZnO films," Materials Science and Engineering: $R$ : Reports, vol. 62, no. 1, pp. 1-35, 2008.

[11] B. B. Straumal, A. A. Mazilkin, S. G. Protasova et al., "Magnetization study of nanograined pure and $\mathrm{Mn}$-doped $\mathrm{ZnO}$ films: formation of a ferromagnetic grain-boundary foam," Physical Review B, vol. 79, no. 20, Article ID 205206, 2009.

[12] T. Tietze, M. Gacic, G. Schütz, G. Jakob, S. Brück, and E. Goering, "XMCD studies on $\mathrm{Co}$ and $\mathrm{Li}$ doped $\mathrm{ZnO}$ magnetic semiconductors," New Journal of Physics, vol. 10, Article ID 055009, 2008.

[13] L. I. Burova, N. S. Perov, A. S. Semisalova et al., "Effect of the nanostructure on room temperature ferromagnetism and resistivity of undoped $\mathrm{ZnO}$ thin films grown by chemical vapor deposition," Thin Solid Films, vol. 520, no. 14, pp. 4580-4585, 2012.

[14] N. H. Hong, J. Sakai, and V. Brizé Hong, "Observation of ferromagnetism at room temperature in $\mathrm{ZnO}$ thin films," 
Journal of Physics: Condensed Matter, vol. 19, no. 3, Article ID 036219, 2007.

[15] K. Ackland, L. M. A. Monzon, M. Venkatesan, and J. M. D. Coey, "Magnetism of nanostructured $\mathrm{CeO}_{2}$," IEEE Transactions on Magnetics, vol. 47, no. 10, pp. 3509-3512, 2011.

[16] Y. L. Zheng, C. M. Zhen, X. Q. Wang, L. Ma, X. L. Li, and D. L. Hou, "Room-temperature ferromagnetism observed in alumina films," Solid State Sciences, vol. 13, no. 8, pp. 1516-1519, 2011.

[17] C. Z. Wang, Z. Chen, Y. He, L. Y. Li, and D. Zhang, "Structure, morphology and properties of Fe-doped $\mathrm{ZnO}$ films prepared by facing-target magnetron sputtering system," Applied Surface Science, vol. 255, no. 15, pp. 6881-6887, 2009.

[18] J. M. A. Almeida, P. E. C. Santos, L. P. Cardoso, and C. T. Meneses, "A simple method to obtain Fe-doped $\mathrm{CeO}_{2}$ nanocrystals at room temperature," Journal of Magnetism and Magnetic Materials, vol. 327, pp. 185-188, 2013.

[19] S. Y. Sokovnin, V. G. Il'ves, A. I. Surdo, I. I. Mil'man, and M. I. Vlasov, "Effect of iron doping on the properties of nanopowders and coatings on the basis of $\mathrm{Al}_{2} \mathrm{O}_{3}$ produced by pulsed electron beam evaporation," Nanotechnologies in Russia, vol. 8, no. 7-8, pp. 466-481, 2013.

[20] V. G. Kytin, V. A. Kulbachinskii, D. S. Glebov, L. I. Burova, A. R. Kaul, and O. V. Reukova, "The conductivity and magnetic properties of zinc oxide thin films doped with cobalt," Semiconductors, vol. 44, no. 2, pp. 155-160, 2010.

[21] G. Y. Ahn, S.-I. Park, and C. S. Kim, "Enhanced ferromagnetic properties of diluted Fe doped $\mathrm{ZnO}$ with hydrogen treatment," Journal of Magnetism and Magnetic Materials, vol.303, no. 2, pp. e329-e331, 2006.

[22] W. Zhang, J. Zhao, Z. Liua, and Z. Liu, "Structural, optical and magnetic properties of $\mathrm{Zn}_{1-x} \mathrm{Fe}_{x} \mathrm{O}$ powders by sol-gel method," Applied Surface Science, vol. 284, pp. 49-52, 2013.

[23] F. Wang, W.-W. Huang, S.-Y. Li, A.-Q. Lian, X.-T. Zhang, and W. Cao, "The magnetic properties of $\mathrm{Fe}_{x} \mathrm{Zn}_{1-x} \mathrm{O}$ synthesized via the solid-state reaction route: experiment and theory," Journal of Magnetism and Magnetic Materials, vol. 340, pp. 5-9, 2013.

[24] X. C. Wang, W. B. Mi, and D. F. Kuang, "Microstructure, magnetic and optical properties of sputtered polycrystalline ZnO films with Fe addition," Applied Surface Science, vol. 256, no. 6, pp. 1930-1935, 2010.

[25] R. Elilarassi and G. Chandrasekaran, "Synthesis and characterization of ball milled Fe-doped $\mathrm{ZnO}$ diluted magnetic semiconductor," Optoelectronics Letters, vol. 8, no. 2, pp. 109112, 2012.

[26] Y. Kimishima, M. Ueharaa, K. Iriea et al., "Production of bulk dilute ferromagnetic semiconductor by mechanical milling," Journal of Magnetism and Magnetic Materials, vol. 320, no. 20, pp. e674-e677, 2008.

[27] A. K. Srivastavaa, M. Deepaa, N. Bahadura, and M. S. Goyat, "Influence of Fe doping on nanostructures and photoluminescence of sol-gel derived ZnO," Materials Chemistry and Physics, vol. 114, no. 1, pp. 194-198, 2009.

[28] P. Dhiman, J. Chand, A. Kumar, R. K. Kotnala, K. M. Batoo, and M. Singh, "Synthesis and characterization of novel Fe@ZnO nanosystem," Journal of Alloys and Compounds, vol. 578, pp. 235-241, 2013.

[29] H. Gu, Y. Jiang, and M. Yan, "Defect-induced room temperature ferromagnetism in Fe and $\mathrm{Na}$ co-doped $\mathrm{ZnO}$ nanoparticles," Journal of Alloys and Compounds, vol. 521, pp. 90-94, 2012.

[30] T. Pandiyarajan, R. Udayabhaskar, and B. Karthikeyan, "Microstructure and enhanced exciton-phonon coupling in $\mathrm{Fe}$ doped ZnO nanoparticles," Spectrochimica Acta A: Molecular and Biomolecular Spectroscopy, vol. 103, pp. 173-178, 2013.

[31] S. M. Ramay, M. Saleem, S. Atiq et al., "RKKY magnetic interactions in chemically synthesized $\mathrm{Zn}_{0.95-x} \mathrm{Fe}_{0.05} \mathrm{Al}_{x} \mathrm{O}(x=0,0.03$, 0.05, 0.07) nanocrystallites," Arabian Journal of Chemistry, 2013.

[32] R. Saleh, N. F. Djaja, and S. P. Prakoso, "The correlation between magnetic and structural properties of nanocrystalline transition metal-doped $\mathrm{ZnO}$ particles prepared by the co-precipitation method," Journal of Alloys and Compounds, vol. 546, pp. 48-56, 2013.

[33] R. Saleh, S. P. Prakoso, and A. Fishli, "The influence of Fe doping on the structural, magnetic and optical properties of nanocrystalline $\mathrm{ZnO}$ particles," Journal of Magnetism and Magnetic Materials, vol. 324, no. 5, pp. 665-670, 2012.

[34] A. P. Thurber, G. Alanko, G. L. Beausoleil II, K. N. Dodge, C. B. Hanna, and A. Punnoose, "Unusual crystallite growth and modification of ferromagnetism due to aging in pure and doped ZnO nanoparticles," Journal of Applied Physics, vol. 111, no. 7, Article ID 07C319, 2012.

[35] B. Panigrahy, M. Aslam, and D. Bahadur, "Effect of Fe doping concentration on optical and magnetic properties of $\mathrm{ZnO}$ nanorods," Nanotechnology, vol. 23, no. 11, Article ID 115601, 2012.

[36] R. Hong, H. Wen, C. Liu, J. Chen, and J. Liao, "Dopant concentration dependence of structure, optical, and magnetic properties of ZnO:Fe thin films," Journal of Crystal Growth, vol. 314, no. 1, pp. 30-33, 2011.

[37] P. Dhiman, S. K. Sharma, M. Knobel, R. Ritu, and M. Singh, "Magnetic properties of Fe doped $\mathrm{ZnO}$ nanosystems synthesized by solution combustion method," Research Journal of Recent Sciences, vol. 1, no. 8, pp. 48-52, 2012.

[38] M. V. Limaye, S. B. Singh, R. Das, P. Poddar, and S. K. Kulkarni, "Room temperature ferromagnetism in undoped and Fe doped $\mathrm{ZnO}$ nanorods: microwave-assisted synthesis," Journal of Solid State Chemistry, vol. 184, no. 2, pp. 391-400, 2011.

[39] C. S. Prajapati, A. Kushwaha, and P. P. Sahay, "Influence of Fe doping on the structural, optical and acetone sensing properties of sprayed $\mathrm{ZnO}$ thin films," Materials Research Bulletin, vol. 48, no. 7, pp. 2687-2695, 2013.

[40] S. George, S. Pokhrel, T. Xia et al., "Use of a rapid cytotoxicity screening approach to engineer a safer zinc oxide nanoparticle through iron doping," ACS Nano, vol. 4, no. 1, pp. 15-29, 2010.

[41] D. Karmakar, S. K. Mandal, R. M. Kadam et al., "Ferromagnetism in Fe-doped $\mathrm{ZnO}$ nanocrystals: experiment and theory," Physical Review B, vol. 75, no. 14, Article ID 144404, 2007.

[42] A. Franco Jr. and T. E. P. Alvesb, "Room temperature ferromagnetism in combustion reaction prepared iron-doped zinc oxide nanoparticles," Materials Science in Semiconductor Processing, vol. 16, no. 6, pp. 1804-1807, 2013.

[43] J. Anghel, A. Thurber, D. A. Tenne, C. B. Hanna, and A. Punnoose, "Correlation between saturation magnetization, bandgap, and lattice volume of transition metal $(\mathrm{M}=\mathrm{Cr}$, $\mathrm{Mn}, \mathrm{Fe}, \mathrm{Co}$, or $\mathrm{Ni}$ ) doped $\mathrm{Zn}_{1-x} \mathrm{M}_{x} \mathrm{O}$ nanoparticles," Journal of Applied Physics, vol. 107, no. 9, Article ID 09E314, 2010.

[44] C. Xia, C. Hu, Y. Tian, B. Wan, J. Xu, and X. He, "Roomtemperature ferromagnetic properties of $\mathrm{Ni}$-doped $\mathrm{ZnO}$ rod arrays," Physica E: Low-dimensional Systems and Nanostructures, vol. 42, no. 8, pp. 2086-2090, 2010.

[45] Z.-R. Wei, Z.-Q. Li, and G.-Y. Dong, "Origin of hightemperature ferromagnetism in $\mathrm{Zn}_{0.98} \mathrm{Fe}_{0.02} \mathrm{O}$ alloys prepared by hydrothermal method," Journal of Magnetism and Magnetic Materials, vol. 320, no. 6, pp. 916-918, 2008. 
[46] H. Liu, J. Yang, Y. Zhang, Y. Wang, and M. Wei, "Ferromagnetism and exchange bias in Fe-doped $\mathrm{ZnO}$ nanocrystals," Materials Chemistry and Physics, vol. 112, no. 3, pp. 1021-1023, 2008.

[47] X. X. Wei, C. Song, K. W. Geng, F. Zeng, B. He, and F. Pan, "Local Fe structure and ferromagnetism in Fe-doped $\mathrm{ZnO}$ films," Journal of Physics: Condensed Matter, vol. 18, no. 31, p. 7471, 2006.

[48] Y. Lin, D. Jiang, F. Lin, W. Shi, and X. Ma, "Fe-doped ZnO magnetic semiconductor by mechanical alloying," Journal of Alloys and Compounds, vol. 436, no. 1-2, pp. 30-33, 2007.

[49] H. Liu, J. Yang, Y. Zhang, L. Yang, M. Wei, and X. Ding, "Structure and magnetic properties of Fe-doped $\mathrm{ZnO}$ prepared by the sol-gel method," Journal of Physics: Condensed Matter, vol. 21, no. 14, Article ID 145803, 2009.

[50] D. Y. Inamdar, A. K. Pathak, I. Dubenko, N. Ali, and S. Mahamuni, "Room temperature ferromagnetism and photoluminescence of Fe Doped $\mathrm{ZnO}$ nanocrystals," The Journal of Physical Chemistry C, vol. 115, no. 48, pp. 23671-23676, 2011.

[51] S. J. Han, J. W. Song, C. H. Yang et al., "A key to roomtemperature ferromagnetism in Fe-doped $\mathrm{ZnO}: \mathrm{Cu}$," Applied Physics Letters, vol. 81, no. 22, p. 4212, 2002.

[52] P. K. Sharma, R. K. Dutta, A. C. Pandey, S. Layek, and H. C. Verma, "Effect of iron doping concentration on magnetic properties of $\mathrm{ZnO}$ nanoparticles," Journal of Magnetism and Magnetic Materials, vol. 321, no. 17, pp. 2587-2591, 2009.

[53] M. Bouloudenine, N. Viart, S. Colis, J. Kortus, and A. Dinia, "Antiferromagnetism in bulk $\mathrm{Zn}_{1-x} \mathrm{Co}_{x} \mathrm{O}$ magnetic semiconductors prepared by the coprecipitation technique," Applied Physics Letters, vol. 87, no. 5, Article ID 052501, 2005.

[54] P. Sati, C. Deparis, C. Morhain, S. Schafer, and A. Stepanov, "Antiferromagnetic interactions in single crystalline $\mathrm{Zn}_{1-x} \mathrm{Co}_{x} \mathrm{O}$ thin films," Physical Review Letters, vol. 98, Article ID 137204, 2007.

[55] T. Fukumura, Z. Jin, M. Kawasaki et al., "Magnetic properties of Mn-doped ZnO," Applied Physics Letters, vol. 78, no. 7, pp. 958-960, 2001.

[56] J. H. Park, M. G. Kim, H. M. Jang, S. R. Yu, and Y. M. Kim, “Cometal clustering as the origin of ferromagnetism in Co-doped ZnO thin films," Applied Physics Letters, vol. 84, no. 8, pp. 13381340, 2004.

[57] C. N. R. Rao and F. L. Deepak, "Absence of ferromagnetism in $\mathrm{Mn}$ - and Co-doped ZnO," Journal of Materials Chemistry, vol. 15, no. 5, pp. 573-578, 2005.

[58] J. M. D. Coey, M. Venkatesan, and C. B. Fitzgerald, "Donor impurity band exchange in dilute ferromagnetic oxides," Nature Materials, vol. 4, no. 2, pp. 173-179, 2005.

[59] S. Y. Sokovnin and V. G. Il'ves, Using of Pulsed Electron Beam for Producing Nanopowders of some Oxides Metals, RIO UB RAS, Yekaterinburg, Russia, 2012, http://ubras.uran.ru/node/2612, http://ubras.uran.ru/sites/default/files/u66/Sokovnin_Orig_1.jpg.

[60] S. Yu. Sokovnin and V. Il'ves, "Production of nanopowders using pulsed electron beam," Ferroelectrics, vol. 436, no. 1, pp. 101-107, 2012.

[61] B. Aleman, Y. Ortega, J. A. Garcia, P. Fernandez, and J. Piqueras, "Fe solubility, growth mechanism, and luminescence of Fe doped $\mathrm{ZnO}$ nanowires and nanorods grown by evaporationdeposition," Journal of Applied Physics, vol. 110, no. 1, Article ID 014317, 2011.

[62] S.-Y. Seo, C.-H. Kwak, S.-H. Kim et al., "Local structural, magnetic, and optical properties of $\mathrm{Zn}_{1-x} \mathrm{Fe}_{x} \mathrm{O}$ thin films," Journal of Crystal Growth, vol. 312, no. 14, pp. 2093-2097, 2010.
[63] P. Wu, G. Saraf, Y. Lu et al., "Ferromagnetism in Fe-implanted a-plane ZnO films," Applied Physics Letters, vol. 89, no. 1, Article ID 012508, 2006.

[64] B. B. Straumal, S. G. Protasova, A. A. Mazilkin et al., "Ferromagnetic behaviour of Fe-doped $\mathrm{ZnO}$ nanograined films," Beilstein Journal of Nanotechnology, vol. 4, no. 1, pp. 361-369, 2013.

[65] S. Banerjee, M. Mandal, N. Gayathri, and M. Sardar, "Enhancement of ferromagnetism upon thermal annealing in pure $\mathrm{ZnO}$," Applied Physics Letters, vol. 91, no. 18, Article ID 182501, 2007.

[66] A. J. Behan, A. Mokhtari, H. J. Blythe et al., "Two magnetic regimes in doped $\mathrm{ZnO}$ corresponding to a dilute magnetic semiconductor and a dilute magnetic insulator," Physical Review Letters, vol. 100, no. 4, Article ID 047206, 2008.

[67] N. Khare, M. J. Kappers, M. Wei, M. G. Blamire, and J. L. MacManus-Driscoll, "Defect-induced ferromagnetism in Codoped ZnO," Advanced Materials, vol. 18, no. 11, pp. 1449-1452, 2006.

[68] C. Song, K. W. Geng, F. Zeng et al., "Giant magnetic moment in an anomalous ferromagnetic insulator: Co-doped $\mathrm{ZnO}$," Physical Review B, vol. 73, no. 2, Article ID 024405, 2006.

[69] C. Song, F. Zeng, Y. X. Shen et al., "Local Co structure and ferromagnetism in ion-implanted Co-doped $\mathrm{LiNbO}_{3}$," Physical Review B, vol. 73, no. 17, Article ID 172412, 2006.

[70] C. N. Wu, T. S. Wu, S. Y. Huang et al., "Ferromagnetism in cluster free, transition metal doped high $\kappa$ dilute magnetic oxides: films and nanocrystals," Journal of Applied Physics, vol. 113, no. 17, Article ID 17C309, 2013.

[71] C. Song and F. Pan, "Metal-doped magnetic oxides," in Transition Semiconductors and Semimetals, vol. 88, chapter 7, pp. 227259, Elsevier, Philadelphia, Pa, USA, 2013.

[72] D. Chakraborti, S. Ramachandran, G. Trichy, J. Narayan, and J. T. Prater, "Magnetic, electrical, and microstructural characterization of $\mathrm{ZnO}$ thin films codoped with $\mathrm{Co}$ and $\mathrm{Cu}$," Journal of Applied Physics, vol. 101, no. 5, Article ID 053918, 2007.

[73] D. Chakraborti, G. R. Trichy, J. T. Prater, and J. Narayan, "The effect of oxygen annealing on $\mathrm{ZnO}: \mathrm{Cu}$ and $\mathrm{ZnO}:(\mathrm{Cu}, \mathrm{Al})$ diluted magnetic semiconductors," Journal of Physics D: Applied Physics, vol. 40, no. 24, pp. 7606-7613, 2007.

[74] P. K. Sharma, R. K. Dutta, A. C. Pandey, S. Layek, and H. C. Verma, "Effect of iron doping concentration on magnetic properties of $\mathrm{ZnO}$ nanoparticles," Journal of Magnetism and Magnetic Materials, vol. 321, no. 17, pp. 2587-2591, 2009.

[75] K. Sato, L. Bergqvist, J. Kudrnovský et al., "First-principles theory of dilute magnetic semiconductors," Reviews of Modern Physics, vol. 82, no. 2, pp. 1633-1690, 2010.

[76] X. Chen, Z. Zhou, K. Wang et al., "Ferromagnetism in Fe-doped tetra-needle like $\mathrm{ZnO}$ whiskers," Materials Research Bulletin, vol. 44, no. 4, pp. 799-802, 2009.

[77] C. Liu, D. Meng, H. Pang et al., "Influence of Fe-doping on the structural, optical and magnetic properties of $\mathrm{ZnO}$ nanoparticles," Journal of Magnetism and Magnetic Materials, vol. 324, no. 20, pp. 3356-3360, 2012.

[78] Y. Q. Wang, S. L. Yuan, L. Liu et al., "Ferromagnetism in Fedoped ZnO bulk samples," Journal of Magnetism and Magnetic Materials, vol. 320, no. 8, pp. 1423-1426, 2008.

[79] X. C. Wang, W. B. Mi, and D. F. Kuang, "Microstructure, magnetic and optical properties of sputtered polycrystalline $\mathrm{ZnO}$ films with Fe addition," Applied Surface Science, vol. 256, no. 6, pp. 1930-1935, 2010.

[80] J. M. Coey, M. Venkatesan, and C. B. Fitzgerald, "Donor impurity band exchange in dilute ferromagnetic oxides," Nature Materials, vol. 4, no. 2, pp. 173-179, 2005. 
[81] S. Y. Sokovnin, V. G. Il'Ves, A. I. Medvedev, and A. M. Murzakaev, "Investigation of properties of $\mathrm{ZnO}-\mathrm{Zn}-\mathrm{Cu}$ nanopowders obtained by pulsed electron evaporation," Inorganic Materials: Applied Research, vol. 4, no. 5, pp. 410-419, 2013.

[82] J. M. D. Coey, K. Wongsaprom, J. Alaria, and M. Venkatesan, "Charge-transfer ferromagnetism in oxide nanoparticles," Journal of Physics D: Applied Physics, vol. 41, no. 13, Article ID 134012, 2008.

[83] J. M. Coey, P. Stamenov, R. D. Gunning, M. Venkatesan, and K. Paul, "Ferromagnetism in defect-ridden oxides and related materials," New Journal of Physics, vol. 12, no. 5, Article ID 053025, 2010.

[84] L. Y. Li, Y. H. Cheng, X. G. Luo et al., "Room-temperature ferromagnetism and the scaling relation between magnetization and average granule size in nanocrystalline $\mathrm{Zn} / \mathrm{ZnO}$ core-shell structures prepared by sputtering," Nanotechnology, vol. 21, no. 14, Article ID 145705, 2010.

[85] X. Zhang, Y. H. Cheng, L. Y. Li et al., "Evidence for high- $T_{c}$ ferromagnetism in $\mathrm{Zn}_{x}(\mathrm{ZnO})_{1-x}$ granular films mediated by native point defects," Physical Review B: Condensed Matter and Materials Physics, vol. 80, no. 17, Article ID 174427, 2009. 

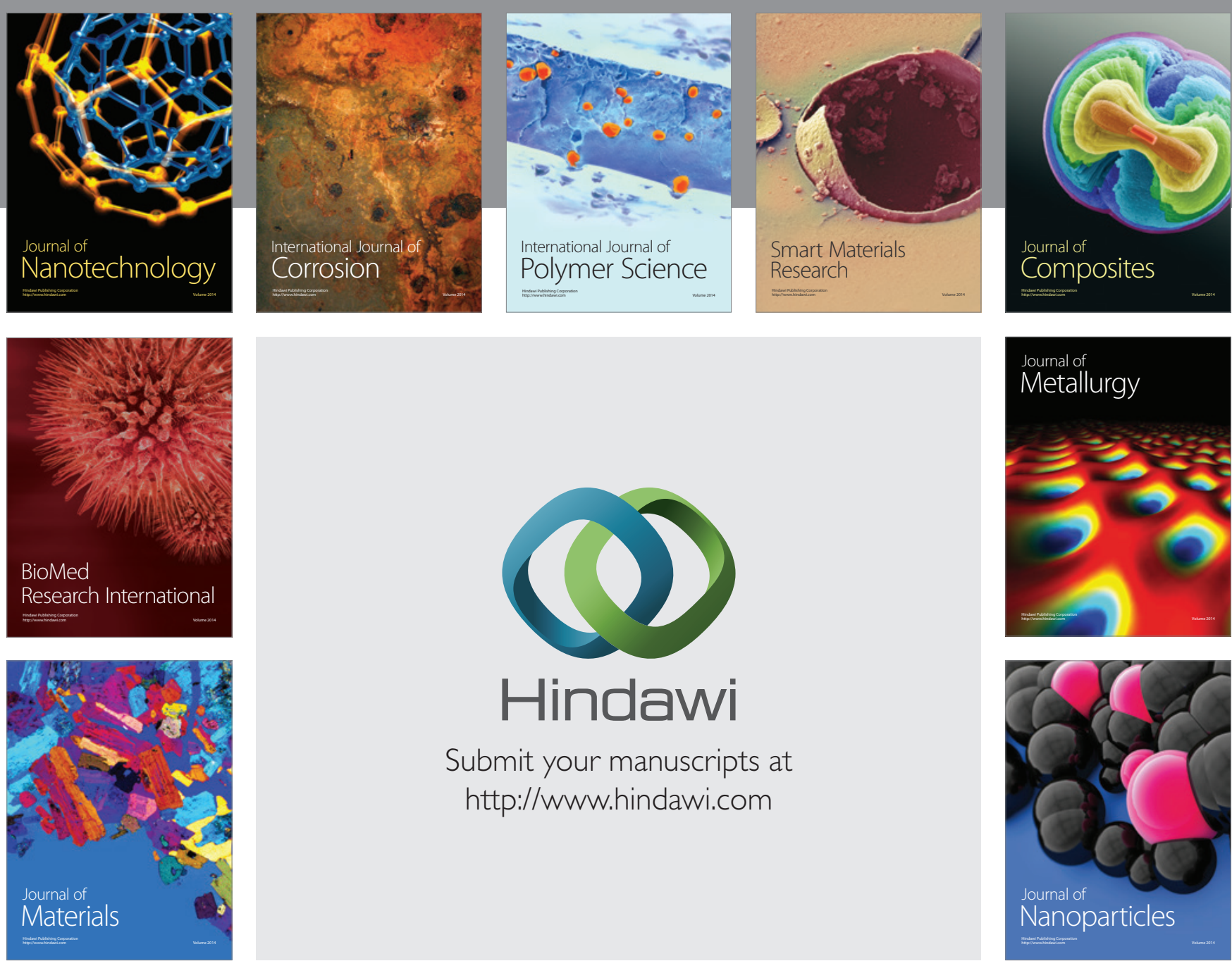

\section{Hindawi}

Submit your manuscripts at

http://www.hindawi.com

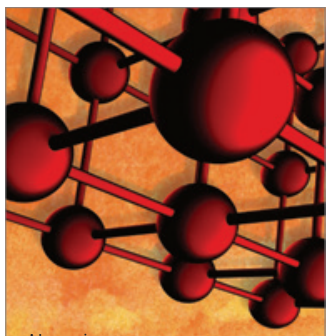

Materials Science and Engineering
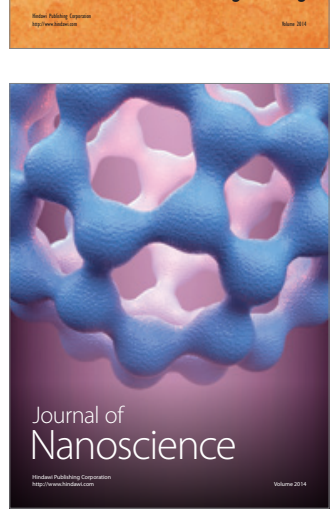
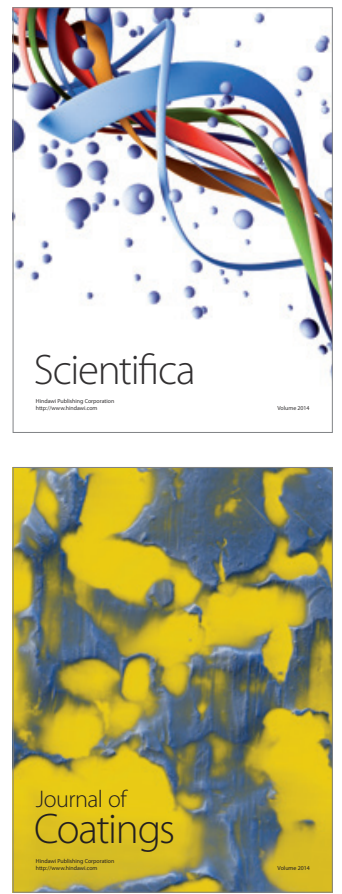
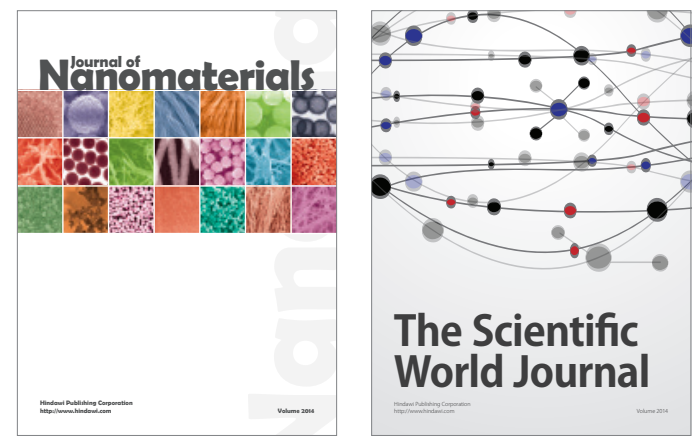

The Scientific World Journal
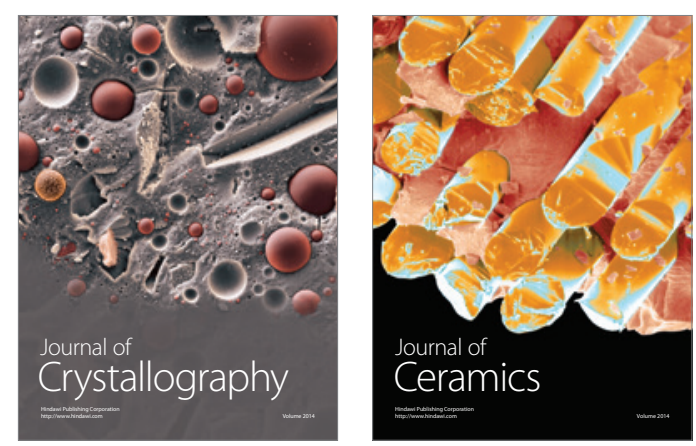
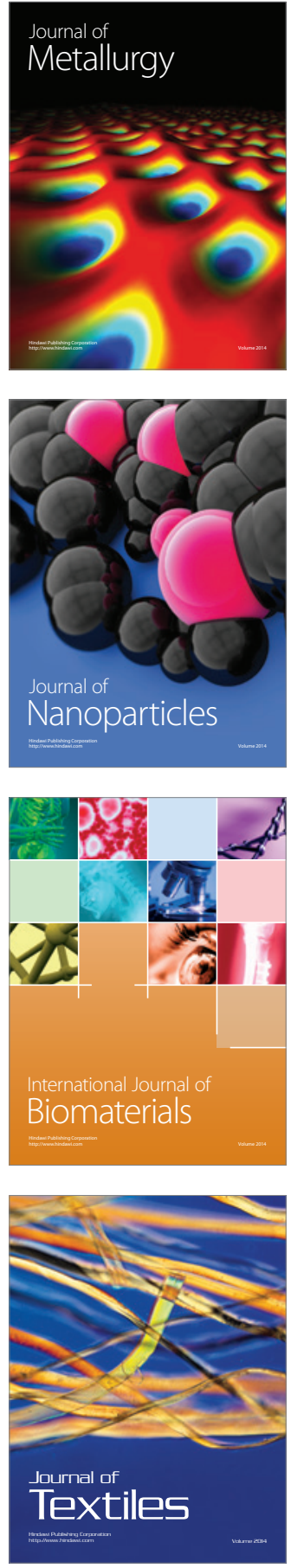